NASA Technical Memorandum 106726

AIAA-94-3343

\title{
A Revolutionary Lunar Space Transportation System Architecture Using Extraterrestrial LOX-Augmented NTR Propulsion
}

Stanley K. Borowski and Robert R. Corban

Lewis Research Center

Cleveland, Ohio

Donald W. Culver, Melvin J. Bulman, and Mel C. McIlwain Aerojet Propulsion Division

Sacramento, California

Prepared for the

30th Joint Propulsion Conference cosponsored by AIAA, ASME, SAE, and ASEE

Indianapolis, Indiana, June 27-29, 1994

ational Aeronautics and

Space Administration 


\title{
A REVOLUTIONARY LUNAR SPACE TRANSPORTATION SYSTEM ARCHITECTURE USING EXTRATERRESTRIAL LOX-AUGMENTED NTR PROPULSION
}

\author{
Stanley K. Borowski* and Robert R. Corban* \\ NASA Lewis Research Center \\ Cleveland, $\mathrm{OH} 44135$ \\ and
}

\author{
Donald W. Culver**, Melvin J. Bulman ${ }^{\star *}$, and Mel C. Mcllwain** \\ Aerojet Propulsion Division \\ Sacramento, CA 95813
}

\begin{abstract}
The concept of a liquid oxygen (LOX)-augmented nuclear thermal rocket (NTR) engine is introduced, and its potential for revolutionizing lunar space transportation system (LTS) performance using extraterrestrial "lunar-derived" liquid oxygen (LUNOX) is outlined. The LOX-augmented NTR (LANTR) represents the marriage of conventional liquid hydrogen $\left(\mathrm{LH}_{2}\right)$-cooled NTR and airbreathing engine technologies. The large divergent section of the NTR nozzle functions as an "afterburner" into which oxygen is injected and supersonically combusted with nuclear preheated hydrogen emerging from the NTR's choked sonic throat--"scramjet propulsion in reverse." By varying the oxygen-to-fuel mixture ratio (MR), the LANTR concept can provide variable thrust and specific impulse (Isp) capability with a $\mathrm{LH}_{2}-$ cooled NTR operating at relatively constant power output. For example, at a $M R=3$, the thrust per engine can be increased by a factor of 2.75 while the Isp decreases by only $30 \%$. With this thrust augmentation option, smaller "easier to develop" NTRs become more acceptable from a mission performance standpoint (e.g., Earth escape gravity losses are reduced and perigee propulsion requirements are eliminated). Hydrogen mass and volume is also reduced resulting in smaller space vehicles. An evolutionary NTR-based lunar architecture, requiring only Shuttle C and/or "in-line" Shuttle-derived launch vehicles (SDVs), would operate initially in an "expendable mode" with $\mathrm{LH}_{2}$-cooled NTR lunar transfer vehicles (LTVs) delivering $80 \%$ more payload on
\end{abstract}

piloted missions than their $\mathrm{LOX} / \mathrm{LH}_{2}$ chemical propulsion counterparts. With the establishment of LUNOX production facilities on the lunar surface and a "fuel/oxidizer" depot in low lunar orbit (LLO), monopropellant NTRs would be outfitted with an oxygen propellant module, feed system and afterburner nozzle for "bipropellant" operation. The LANTR cislunar LTV now transitions to a reusable mode with smaller vehicle and payload doubling benefits on each piloted round trip mission. As the initial lunar outposts grow to centralized bases and settlements with a substantial permanent human presence, a LANTR-powered shuttle capable of 36 to 24 hour "one-way" trip times to the Moon and back becomes possible with initial mass in low Earth orbit (IMLEO) requirements of $\sim 160$ to 240 metric tons, respectively.

\section{INTRODUCTION}

Five years ago, on the 20th anniversary of the Apollo 11 Moon landing, then President Bush proposed a Space Exploration Initiative (SEI) ${ }^{1}$ for the United States which included a permanent space station in low Earth orbit (LEO), a return to the Moon "to stay" early in the 21 st century, and then a journey to Mars before the year 2019. As part of its "90 Day Study",2 the National Aeronautics and Space Administration (NASA) conducted an initial assessment of the space transportation system elements and infrastructure required to move both humans and support equipment from Earth to the surface of the Moon.

"Member AIAA

"*enior Member AlAA 
A reference lunar orbit rendezvous (LOR) mission profile was selected with a space-based, lunar transfer vehicle (LTV) operating between LEO and low lunar orbit (LLO), and a lunar landing vehicle (LLV) for transportation from LLO to the lunar surface and back. ${ }^{3}$ The LTV was partially reusable and, after aerobraking into LEO, was refurbished at the space station which was to serve as a transportation node. A cargo version of the current Space Shuttle (Shuttle C) or an "in-line" Shuttle-derived launch vehicle (SDV) were assumed to be available for Earth-to-orbit transport. A centralized lunar base buildup scenario 4 was also adopted that evolved in time to support substantial science and exploration objectives, as well as, "in-situ" resource production and utilization for eventual base selfsufficiency.

The NASA 90 Day Study was followed by the Synthesis Group report 5 which proposed four different architectural stategies that varied in regard to their emphasis on exploration and science, human presence, space resource utilization, and Moon versus Mars focus. For its reference lunar space transportation system, the Synthesis Group departed from the reusable aerobraked concepts of the
90 Day Study to more "Apollo-like" vehicle configurations operating in an "all propulsive" expendable mission mode. A dual launch Earth orbit rendezvous and dock (EOR\&D) scenario using 150 metric ton (t) heavy lift launch vehicles was adopted for vehicle assembly and a "direct capsule entry" for Earth return was assumed (see Figure 1). This approach eliminated the need for a space station transportation node in LEO.

Concurrent with the 90 Day Study and Synthesis Group assessments, the benefits of using NTR propulsion for lunar space transportation was being assessed at the NASA Lewis Research Center. ${ }^{6}$ With its factor of two advantage in Isp over chemical propulsion and its high engine thrust-to-weight ratio, a NTR-powered LTV could transport a fully-fueled, cargo-laden LLV to the Moon, and return it to LEO after mission completion (see Figure 2) for less IMLEO than even the partially reusable, aerobraked chemical systems baselined in the 90 Day Study. However, due to the low density of $\mathrm{LH}_{2}$ $\left(\sim 71 \mathrm{~kg} / \mathrm{m}^{3}\right)$, the propellant tank(s) on an NTR vehicle can be sizable ( 10 $\mathrm{m}$ in diameter) necessitating large payload shrouds to launch the necessary vehicle components. For example, the main propel-

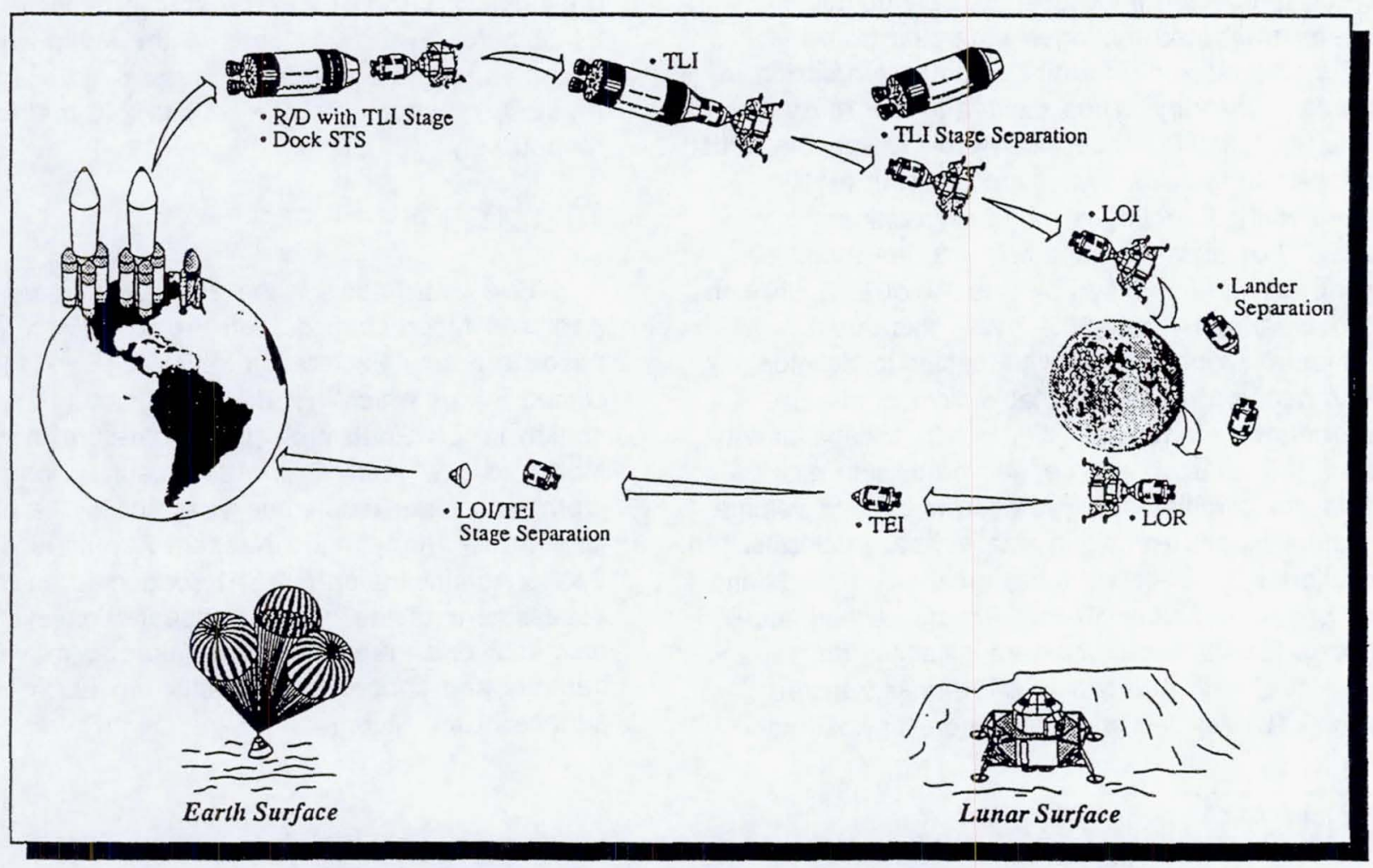

Fig. 1 Dual Launch Earth Orbit Rendezvous Lunar Mission Scenario 


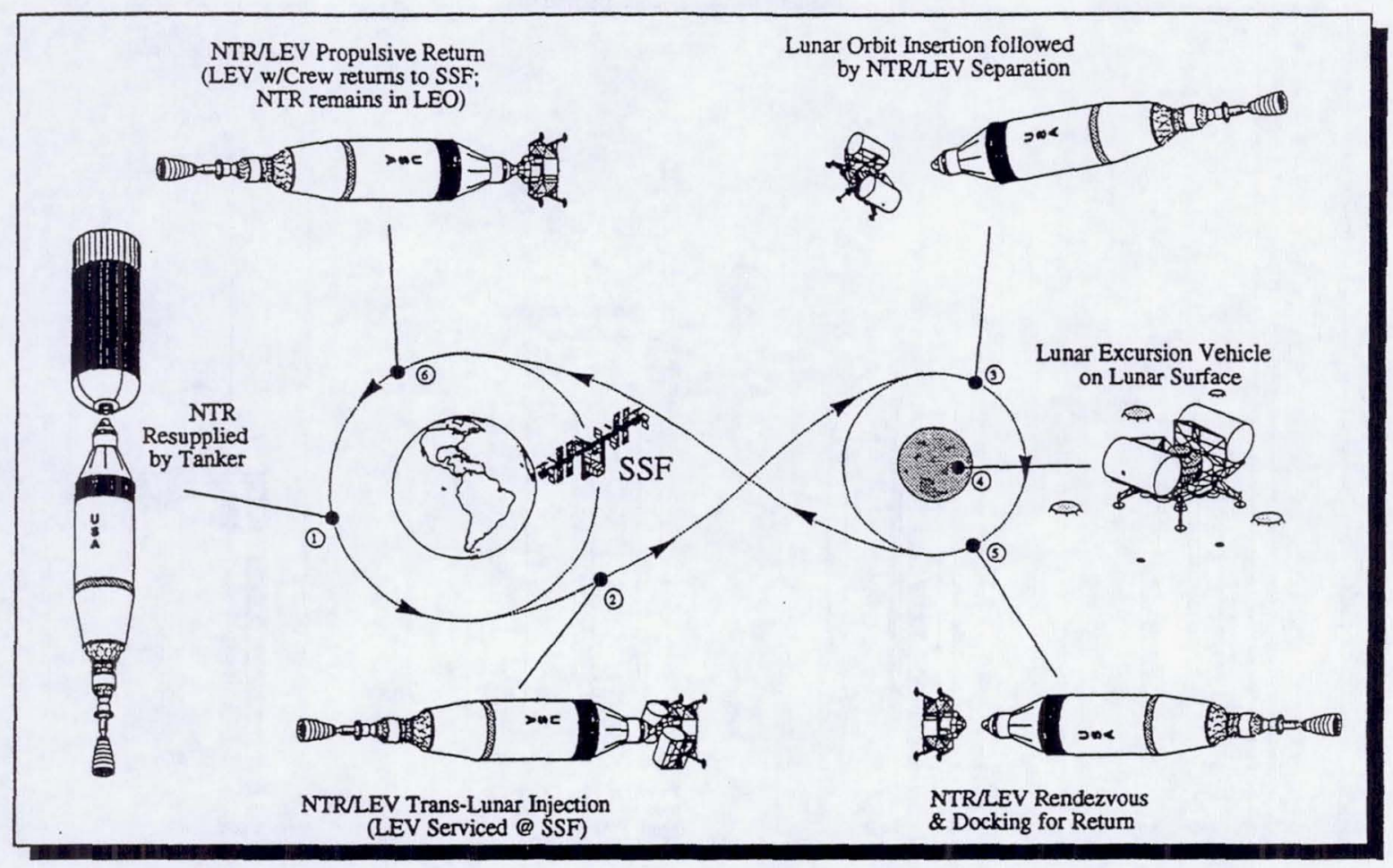

Fig. 2 "Fully Reusable" NTR Lunar Scenario

lant tank on the fully reusable NTR stage shown in Figure 2 requires the larger Shuttle C-Block II payload shroud (see Figure 3) for its launch.

Supporting LEO infrastructure--specifically a propellant depot or expendable propellant tanker-would also be required to complete $\mathrm{LH}_{2}$ fueling of the main propellant tank due to the payload limitations of the Block II configuration. If investment in the "inspace" infrastructure necessary to support reusable transportation system concepts is delayed to reduce "up front" design, development, test, and evaluation (DDT\&E) and production costs, then expendable NTR systems designed to maximize delivered payload on each piloted and cargo mission would help to reduce stage size and cost. Eventually, however, a transition to reusable systems will be necessary if transportation system recurring costs are to be minimized to the point where commercialization and human settlement of the Moon can become practical.

"Lunar-derived" LOX (LUNOX) production has been identified 7,8 as one of the most promising technologies to be developed for the utilization of lunar resources. By providing a local source of LOX for fuel cells, life support systems and $\mathrm{LOX} / \mathrm{LH}_{2}-$ fueled lunar landing vehicles, greater quantities of high value cargo (people, complex equipment and scientific instruments) can be transported in place of bulk LOX propellant. Dramatic reductions in the amount of mass to LEO and the cost of operating the lunar base are therefore expected. The importance of LUNOX for both reducing the direct expense of going to the Moon and increasing the viability of a "self-sufficient" long-term lunar base was highlighted by the Synthesis Group in its Space Resource Utilization architecture.5,9 Previous studies examined the performance and cost benefits of using LUNOX in the LTV portion of the lunar transportation system 10 , and also the viability of LUNOX as a commercial product for shipment to and use in Earth orbit. 11,12

Oxygen is abundant in the lunar regolith $(\sim 45 \%$ by mass $)^{7}$ and can be extracted using a variety of techniques. ${ }^{13}$ A conceptual design of a LUNOX production plant based on hydrogen reduction of ilmenite $\left(\mathrm{FeTiO}_{3}\right)$ is described in Reference 13 and illustrated in Figure 4. Soil or "ilmenite-rich" basalt feedstock is shown being delivered to an automated 


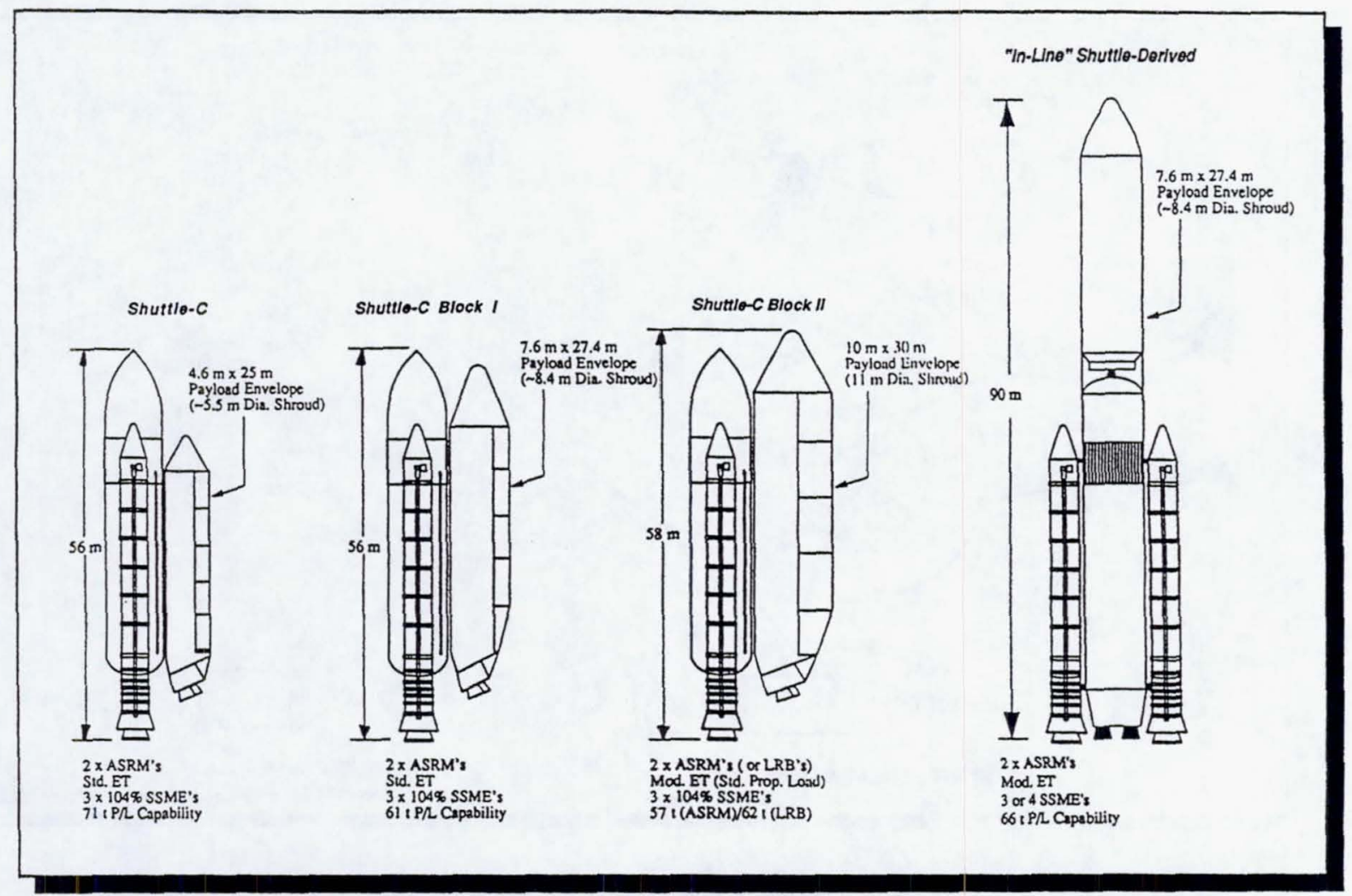

Fig. 3 Options for Lunar Launch Vehicles

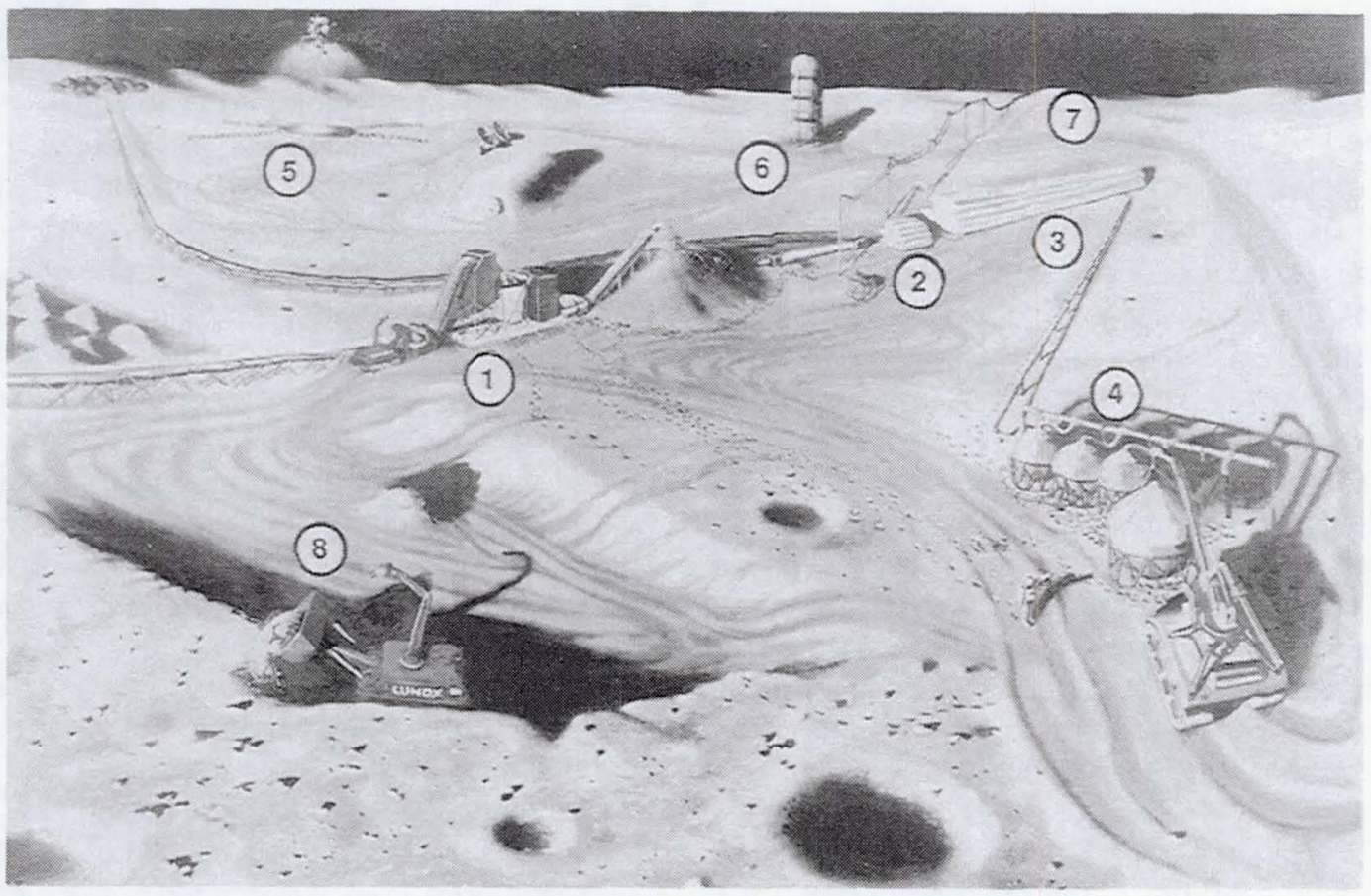

Fig. 4 Artist's Illustration of LUNOX Production Plant Using Hydrogen Reduction of llmenite 
plant (1) where the ilmenite is beneficiated and chemically reduced by hydrogen in a fluidized bed reactor (1) operating at 900 to $1000^{\circ} \mathrm{C}$. Water, residual solids, iron $(\mathrm{Fe})$ and rutile $\left(\mathrm{TiO}_{2}\right)$ are produced with the water being piped to an electrolysis facility (2) where oxygen and hydrogen are separated. The hydrogen is recycled back to react with more ilmenite while the oxygen is liquified (3) and stored in "well-insulated" storage tanks (4). A lunar "ferry" vehicle (5) could transport the LUNOX from the lunar surface to a propellant depot in LLO and return with Earth imported $\mathrm{LH}_{2}(6)$. Power to allow plant operation during the two-week lunar night would be provided by a nuclear reactor located a safe distance (7) from the facility. Teleoperated front-end loaders and regolith haulers (8) would mine and transport $\sim 327 \mathrm{t}$ of lunar soil $(\sim 186 \mathrm{t}$ for basalt feedstock) for each metric ton of oxygen produced. Plant mass and power requirements would be a function of the LUNOX production rate and are discussed later in this paper.

To exploit the high performance capability of the NTR and leverage the benefits of LUNOX, an innovative propulsion concept is proposed which integrates NTR and "supersonic combustion" airbreathing engine technologies to form a LOXaugmented NTR (LANTR) engine. Oxygen injection into the large divergent portion of the NTR nozzle and its combustion with supersonic hydrogen provides the conventional $\mathrm{LH}_{2}$-cooled NTR with a "LOX-afterburner" capability along with a variety of engine, vehicle and mission performance benefits shown in Figure 5.

The implementation strategy we have baselined in this paper is one which uses conventional $\mathrm{LH}_{2}-$ cooled NTRs in an "expendable mode" initially to maximize delivered payload per mission and to reduce IMLEO. This approach allows us to use the Shuttle-C or "in-line" Shuttle-derived vehicle (SDV) for Earth-to-orbit launch of necessary components. Recent analysis 14 of launch vehicle cost trends indicate that, in terms of payload delivered to orbit, the Shuttle $C$ outperforms all other launch vehicles in terms of cost effectiveness. This includes the fully reusable, reduced-payload-capability, Single Stage to Orbit (SSTO) vehicle estimated to cost between $\$ 13$ billion and $\$ 18$ billion dollars. By contrast, the second generation Shuttle $\mathrm{C}$ would cost $\sim \$ 3$ billion

\section{Schematic of LOX-Augmented NTR Propulsion Concept}

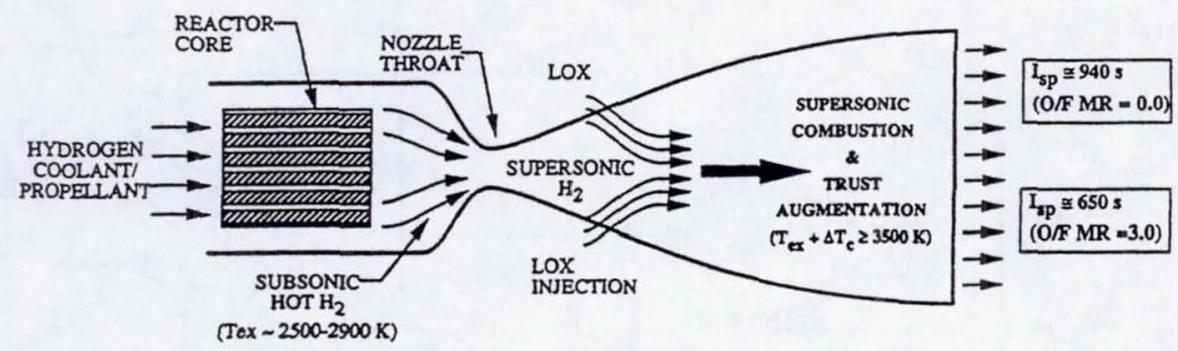

- Variable thrust and Isp capability with $\mathrm{LH}_{2}$-cooled NTR operating at relatively constant power

- Smaller, more afforable, "easier to test" NTRs provide big engine performance (high engine thrust-to-weight reduces g-losses)

- Significant reductions in $\mathrm{LH}_{2}$ propellant tank size, mass and boiloff

- Substantial reductions in overall stage size/allows smaller HLLVs

- Ability to utilize extraterrestrial sources of $\mathrm{O}_{2}$ and $\mathrm{H}_{2}$ (e.g., LUNOX, Phobos $\mathrm{H}_{2} \mathrm{O}$, Mars $\mathrm{CO}_{2}$ and $\mathrm{H}_{2} \mathrm{O}$, and $\mathrm{H}_{2} \mathrm{O}$ from Galilean Satellites) will facilitate human expansion into the solar system

Fig. 5 Benefits of LOX-Augmented NTR Propulsion 
dollars. Our implementation strategy also leverages the increased payload delivery capability of the expendable NTR system to land surface systems dedicated to lunar resource utilization. Our intent is to use LUNOX for refueling of LLVs and LTVs at the earliest possible opportunity 9,15 and to then transition from an expendable to reusable LTS architecture.

This paper describes results from system and mission analysis studies conducted by NASA LeRC and Aerojet in FY94. The paper first describes the LANTR concept together with its operational and performance characteristics. Mission and transportation system ground rules and assumptions are then presented and used in comparing chemical and NTR propulsion systems with and without LOX-augmentation. Next, the improvements in LANTR stage capabilities brought about by refueling, or more appropriately "reoxidizing" in LLO with LUNOX are presented. Mars and outer planetary mission applications, which will be the subject of future papers, are also briefly discussed. Finally, a summary of our findings and the conclusions reached in this study are presented.

\section{THELOX-AUGMENTED NTR CONCEPT}

\section{Operational Characteristics/Performance Capabilities}

The NTR engine considered in this study has three operating modes: thrust with hydrogen propellant, electric power only, and thrust with oxygen and hydrogen propellants. Each operating mode provides a secondary function; electric power is generated by the NTR in both thrust modes, and reactor cooldown at mid-to-low power levels is provided without propellant consumption by the electric power mode. Figure 6 shows a simplified flow schematic of the three operating modes. During the bipropellant thrust mode, oxygen is injected into the supersonic rocket nozzle, where it burns spontaneously with the hot hydrogen there, adding both mass and energy to the rocket exhaust as shown in Figures 5 and 6.

Our trimodal NTR contains a reactor and nozzle to heat the and expand propellant, hydrogen and oxygen feed systems, and a closed Brayton power cycle for engine cooldown, deep throttling, and electric power generation. The hydrogen feed

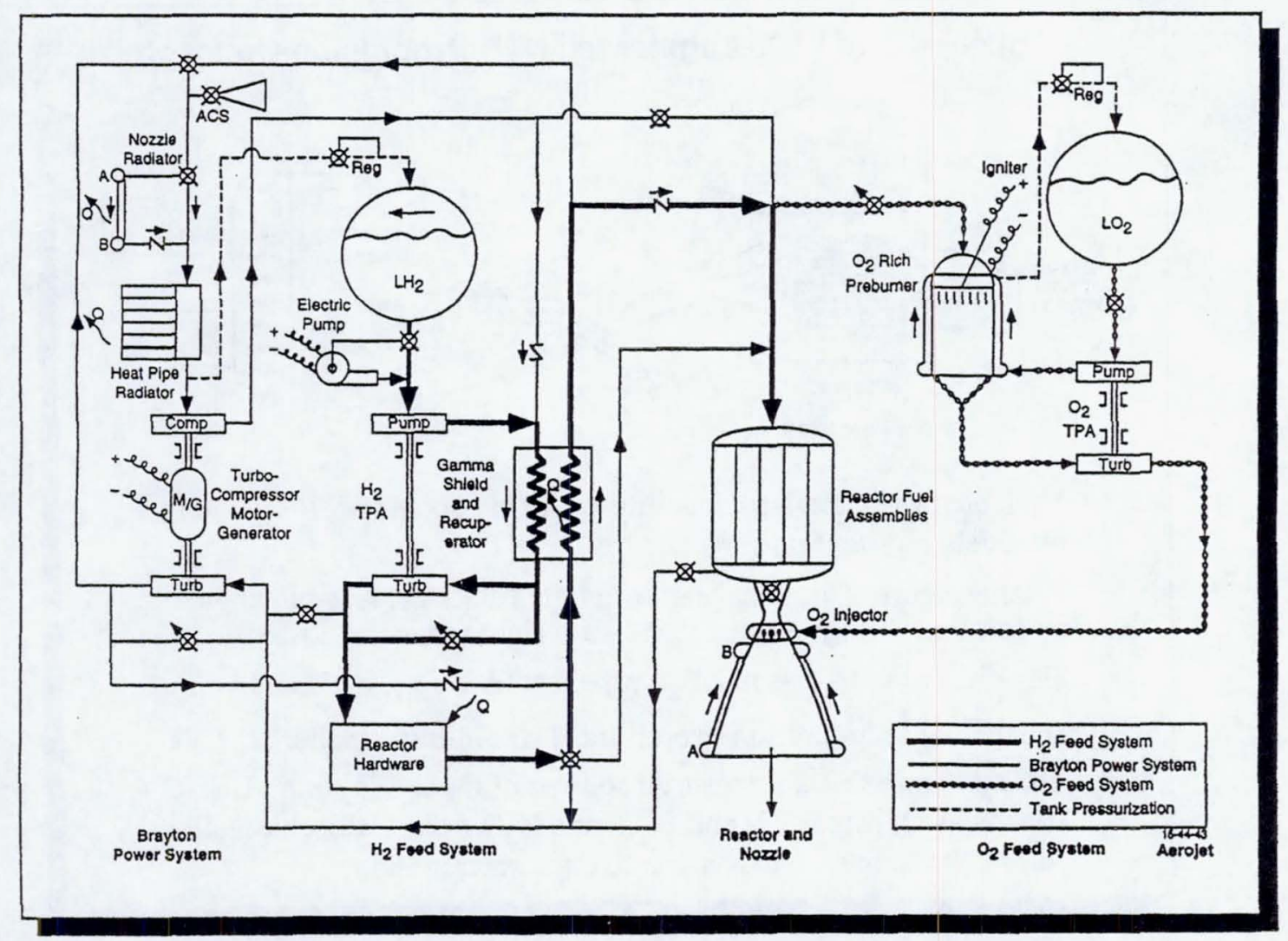

Fig. 6 Trimodal NTR Engine Flow Schematic 
system is powered by engine waste heat with a highly recuperated topping cycle to enable the engine to run with a nozzle inlet pressure of 2000 psia. This reduces engine size and mass, since the recuperator is the reactor's cooled, gamma shadow shieid. The recuperator also provides important safety and performance enhancing functions during start, shutdown, and low power operation. The oxygen feed system uses a topping cycle powered by an oxidizer-rich preburner. Its turbine inlet temperature is low, because it pumps only liquid oxygen. Each feed system pressurizes its own propellant tank by autogeneous gas bleed. The hydrogen system generates electricity by bleeding through the Brayton cycle turbine, which drives an electric motor/generator and a compressor. The compressor is used during closed loop and low power operation for hydrogen gas circulation, reactor cooldown, and electric power generation. Propellant tanks are not pressurized during closed loop operation, and radiators are used to reject waste heat to space.

The subsonic rocket nozzle is fitted with an onoff valve, which is opened to the hot hydrogen gas stream during thrust mode operation and shut during closed loop modes of operation for several reasons. Reactor heat removal at mid-power levels is enhanced by removing heat directly from nuclear fuel assemblies; the closed valve prevents leakage of hydrogen working fluid and any entrained fission gas. At lower power and temperature levels, heat is removed over long durations from the outside wall of the fuel assemblies to maintain system integrity, but any cracked fuel assemblies could otherwise leak unacceptable amounts of fluid to space. Valve leakage is expected to be small over years of operation at low power operation, because its duty is to contain low pressure and temperature gas with a pressurized seal.

An extremely versatile feature of this engine is that it can operate at any propellant mixture ratio (MR) from zero to approximately seven with high performance. Engine thrust is available over a range greater than 100-to-1, because both MR and reactor power are variables. This flexibility matches the needs of many missions. Oxygen injection can change NTR characteristics significantly or very little depending on the MR. It does not disturb nuclear engine operation, because it is injected into the supersonic nozzle. No hydrogen flow variations are possible as long as supersonic oxygen combustion does not unchoke the throat.

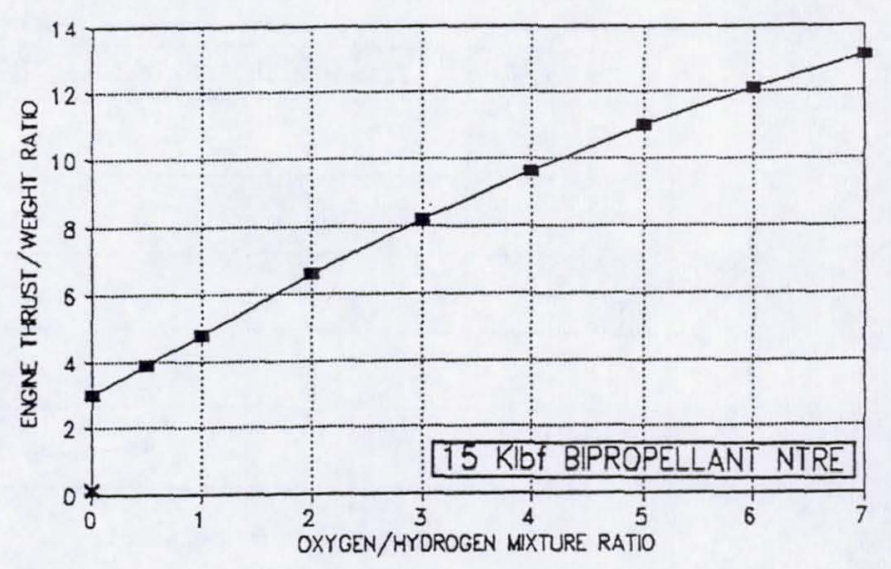

Fig. 7 Variation of Engine Thrust-to-Weight Ratio with $\mathrm{O} / \mathrm{H}$ Mixture Ratio

Figure 7 shows the engine thrust-to-weight ratio $\left(T / W_{\theta}\right)$ versus MR for the LANTR. Engine thrust and $T / W_{\theta}$ increases by $440 \%$ with oxygen injection at $M R=7$. This means that a small nuclear engine can be developed on Earth in affordable test facilities and still provide high thrust for efficient Earth orbit escape. Mixture ratio may be varied during the burn to obtain both acceleration control and the performance benefit of reducing vehicle mass early as suggested in Reference 16. Figures 8 and 9 show that the specific impulse degrades by $45 \%$ at $\mathrm{MR}=7$, but that propellant tank mass and volume is decreased by $540 \%$.

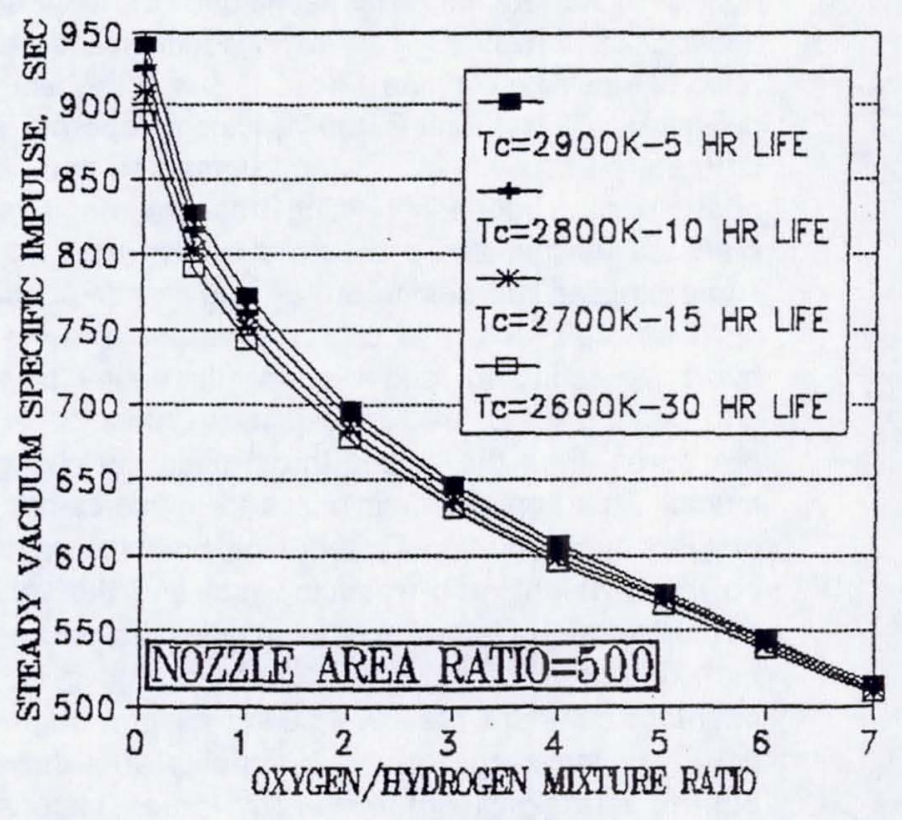

Fig. 8 Variation of LANTR Specific Impulse with $\mathrm{O} / \mathrm{H}$ Mixture Ratio 


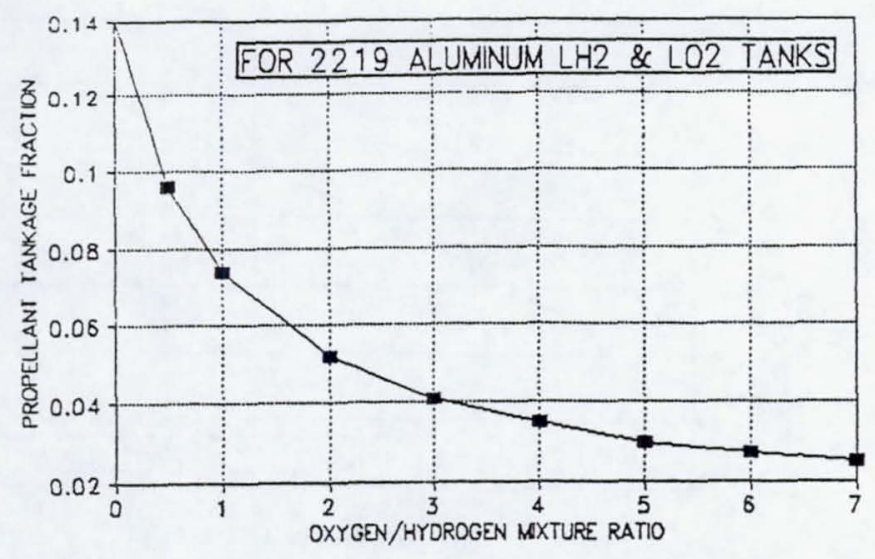

Fig. 9 Variation of Bipropellant Tank Fraction with $\mathrm{O} / \mathrm{H}$ Mixture Ratio

What does this mean in terms of space vehicle performance? First, we can accommodate either volume or mass constrained launch vehicles. For example, we can minimize LTV volume by operating the LANTR at higher MR values. Secondly, we can reduce LTV mass by refueling for the return trip to Earth and still attain specific impulses in the neighborhood of $50 \%$ better than chemical rockets.

\section{NTR LOX-Augmentation Options}

The burning of oxygen in a NTR is not a new idea. It was suggested by Kingsbury16 in 1977. His concept introduced the oxygen subsonically as in a normal rocket engine. This technique has several drawbacks, however. The mass addition and heat release upstream of the throat raises the chamber pressure. This requires the reactor to operate at different pressure levels in the augmented and unaugmented modes affecting heat transfer rates, pressure losses, and pressure stresses, and compromising the design of key engine components, such as the reactor, its pressure vessel, and the hydrogen (coolant) feed system. If reactor power and coolant flows are reduced to maintain equal pressures, then the engine thrust does not change much. This approach minimizes the benefits of oxygen augmentation by reducing both the reactor's power-to-weight ratio (reducing Isp) and the vehicle thrust-to-weight ratio (increasing g-losses and engine burn durations). The NTR could be designed to maintain constant pressure during oxygen augmentation by using a nozzle with a variable area throat, but this is a significant technology issue. Materials selected for use with hot hydrogen have poor oxygen resistance. High stagnation teperatures (>4500 K) and large amounts of atomic oxygen will generate damaging heat fluxes in the nozzle about three times larger than ever achieved in any flight rocket engine. This causes problems for both movable nozzle components and for reactor components subject to any oxygen recirculation in the subsonic plenum. Moreover, the combusion will be incomplete in the subsonic nozzle, because of the high enthalpy of hydrogen exhausted from the reactor. Significant heat release will occur only when gas temperature drops below $3600 \mathrm{~K}$ during expansion in the supersonic nozzle.

The LANTR avoids these difficulties by injecting oxygen downstream of the throat. This isolates the reactor from all oxygen injection effects as long as the throat retains choked flow. This condition is satisfied by controlling mass addition and heat release profiles to keep the flow supersonic. This is a reverse supersonic combusion ramjet (scramjet) with oxidizer injected into hot fuel, and many challenges are the same. Aerojet has recently received U.S. Patent 5,220,787 for its "cascade" scramjet injector. Because our concept is so like a scramjet, we first show how the cascade injector improves this system before discussing problems unique to the LANTR.

Scramjet combustion must proceed rapidly to burn sufficient quantities of fuel before exiting the engine. The rate limiting process is fuel-air mixing, because auto-ignition occurs at the local temperatures. The most effective injection scheme introduces fuel normal to the airstream. This class of injectors are called "normal" or "transverse" and have been studied extensively by researchers 17 over the last $\mathbf{3 0}$ years. Deficiencies were found with these injectors, however. Adequate penetration was achieved only with a large injection flow rate per element, allowing only a few injection sites to avoid over-fueling. The gaseous fuel injection plume presents a high drag shape to the supersonic flow, and a strong shock system develops in the airstream. This shock system has several deleterious effects on the engine. It reduces the total pressure in the air flow and degrades engine performance. Where the bow shock interacts with the boundary layer, flow separation occurs. This forms oblique shocks and a recirculation region in front of the injector. The higher pressure combined with entrained fuel-air combustion generates measured heat fluxes five times higher than the non-injection case.

Figure 10 compares conventional and cascade injector performance. Injectant penetration into the 


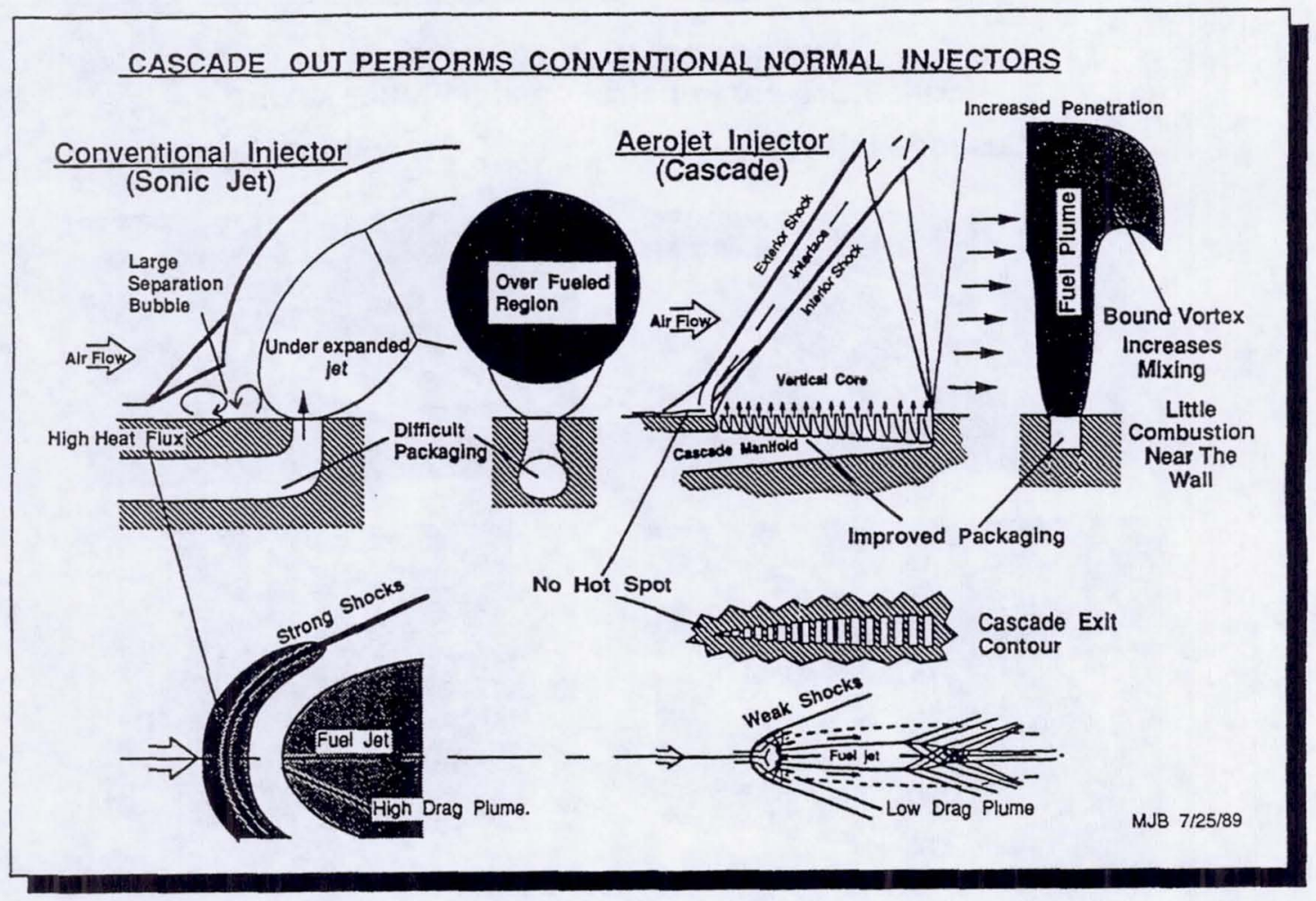

Fig. 10 Benefits of Cascade Injector Concept

airstream from the cascade is greater than from conventional injectors, because fuel is injected through a low drag exit contour, and because the plume retains its narrow width by locally matching nozzle exit pressure to the local pressure in the free stream. This avoids free stream expansion that is typical with under expanded and unstreamlined fuel jets. Figure 11 shows CFD results that compare cascade to conventional injectors. The cascade penetrates farther, and at maximum penetration, the bound vortex system begins rapid lateral fuel movement. Thus, the fuel injected by cascade penetrates farther and spreads laterally faster than when injected by conventional means. Moreover, less fuel finds its way back to the wall with cascade injection, and this keeps the bulk of the combustion away from the engine wall. Reduced fuel flow necessary to achieve required penetration allows more injection sites to be used, which reduces the mixing gap and accelerates the combustion process. Faster combustion enables a shorter engine for the same combustion efficiency, and this lowers engine weight and heat loads that must be absorbed by the engine's thermal management system. Aerojet estimates that the cascade injector increases scramjet net specific impulse by $10 \%$. Each of these benefits apply to the LOX-augmented NTR.
The high enthalpy environment in the LANTR increases the challenge. To avoid choking the nozzle flow, the cascade injector stages oxygen injection and heat release to keep the Mach number constant in the low supersonic range (Mach 1.5-2.0) to minimize Rayleigh losses. The static temperature is allowed to increase up to $3600 \mathrm{~K}$ during this process. At MR values greater than three, the Mach number must be allowed to increase to avoid exceeding $3600 \mathrm{~K}$. Here the process transitions from one with a constant Mach number and increasing temperature to the reverse, one with increasing Mach number at constant temperature, because heat release slows automatically at higher temperatures. This injection strategy minimizes the shock losses, high heat flux regions (hot spots), and Rayleigh losses, thus maximizing performance and life. Figure 12 illustrates conditions in the nozzle during bipropellant and monopropellant NTR thrust modes. Key to this concept are high reactor outlet pressure to suppress molecular dissociation and high nozzle area ratio to provide a high effective nozzle area ratio and thrust coefficient after supersonic combusion losses are included. High pressure enables high area ratio nozzles of reasonable size and weight. 


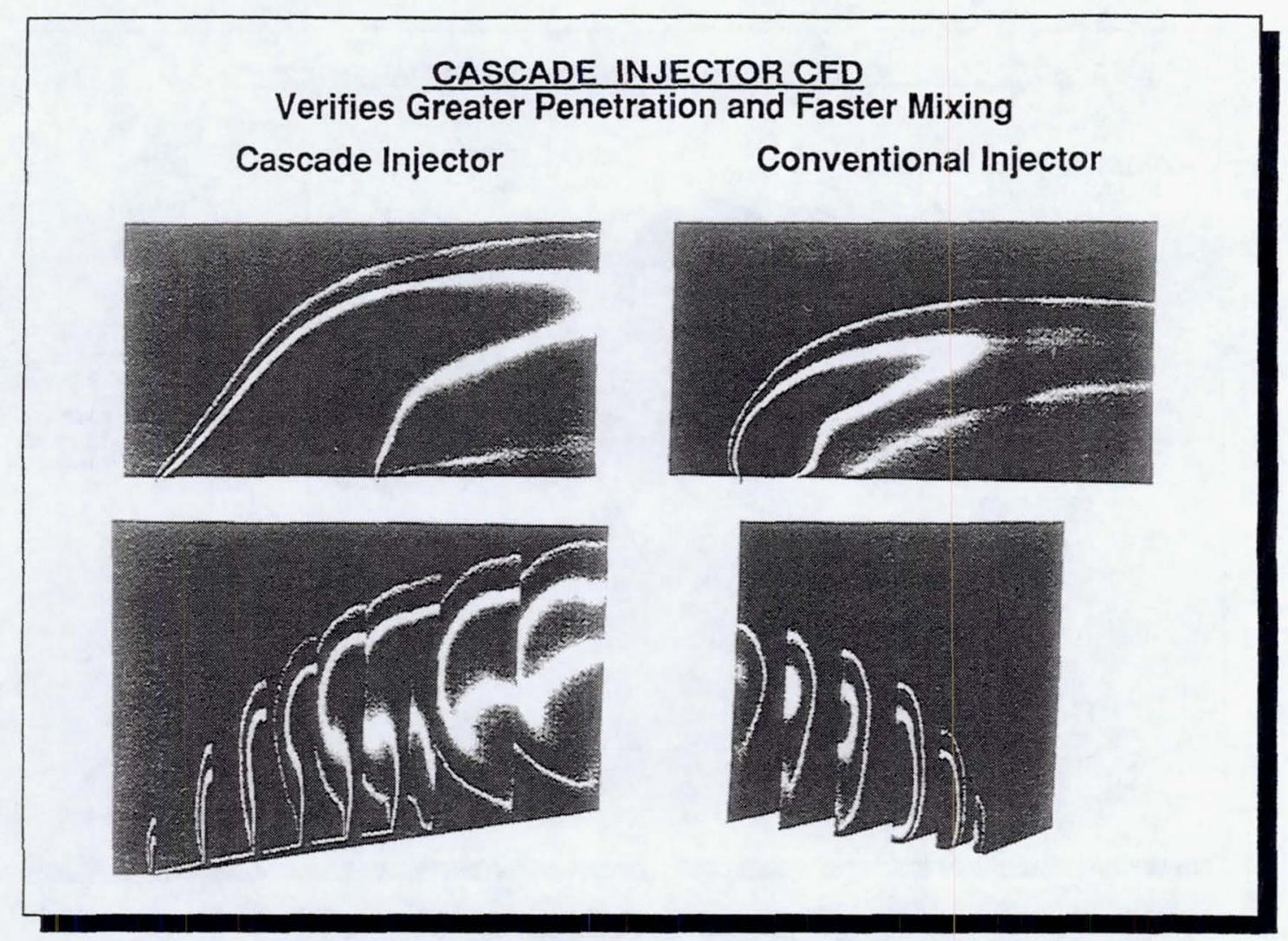

Fig. 11 Cascade Injector CFD Modelling Results

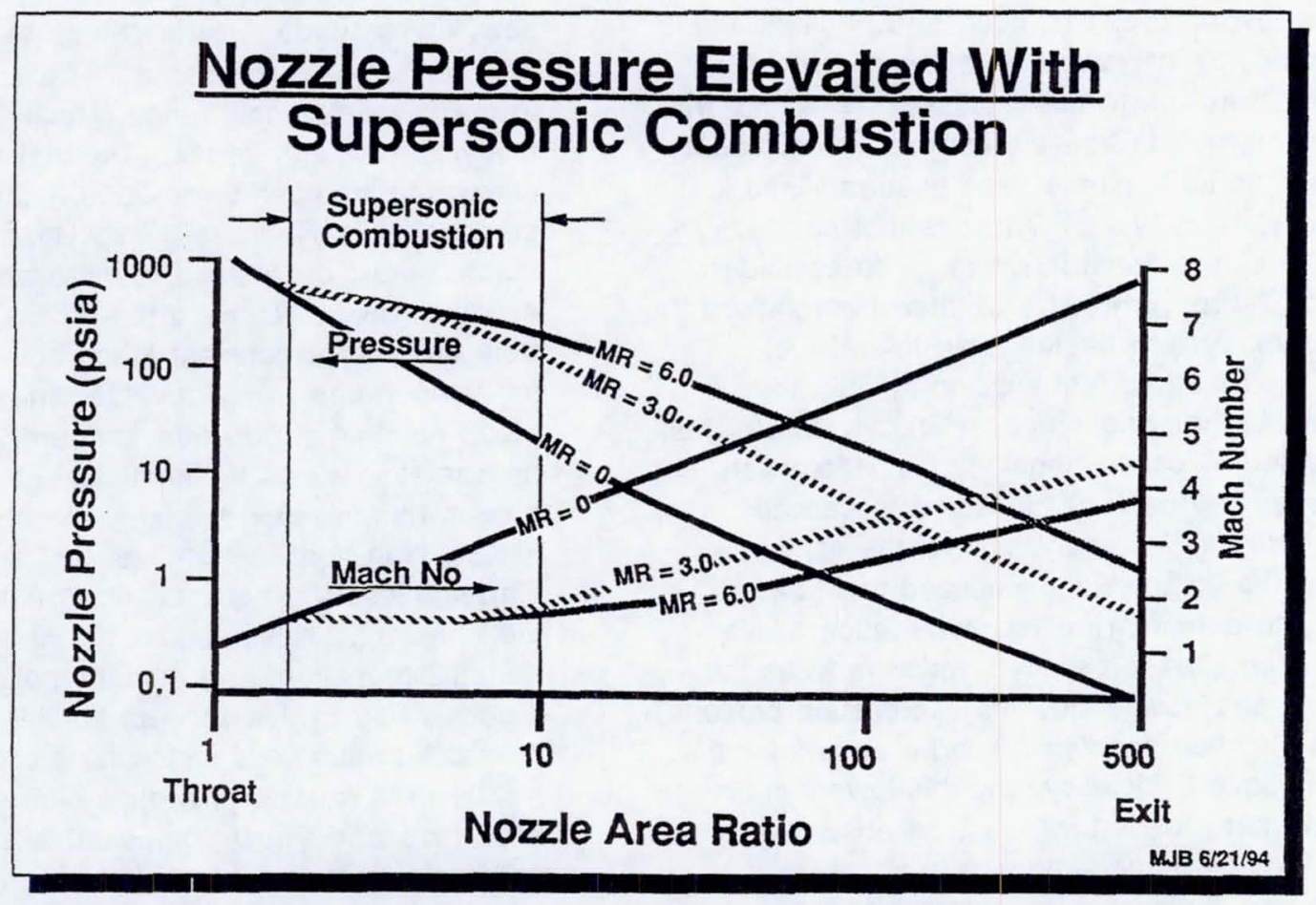

Fig. 12 Nozzle Conditions during Conventional and LOX-Augmented Operation 


\section{LUNAR MISSIONITRANSPORTATION SYSTEM}

\section{GROUND RULES AND ASSUMPTIONS}

The ground rules and assumptions for the reference lunar mission examined in this study are summarized in Table 1. Provided are details on outbound and return payloads, parking orbits, mission velocity change $(\Delta \mathrm{V})$ requirements and duration, and heavy lift launch vehicle (HLLV) characteristics. In addition to the three primary $\Delta \mathrm{V}$ maneuvers (four for the NTR system) indicated, midcourse correction maneuvers are also performed using a storable, bipropellant RCS system. Table 2 includes details on primary and auxiliary propulsion, cryogenic tankage, thermal protection and boiloff rates, and contingency factors used in this study.

An aluminum-lithium alloy "Weldalite" $\left(F_{\mathrm{tu}}=111 \mathrm{ksi}, \rho=0.0976 \mathrm{lbm} / \mathrm{in}^{3}=2700 \mathrm{~kg} / \mathrm{m}^{3}\right)$, has been used in previous NASA contractor studies 18 of expendable, two-stage chemical LTV systems, and is also assumed here for construction of the lunar NTR's $\mathrm{LH}_{2}$ and LOX propellant tanks. Wall thicknesses for the $\mathrm{LH}_{2}$ tanks were calculated based on a 35 psi internal pressure and included hydrostatic loads using a " $3 \mathrm{~g}$ " load factor along with a safety factor of 1.5. A 2.5 percent ullage factor was also assumed in this study. A 50 psi internal pressure was assumed for LOX tanks with a wall thickness of $\sim 0.1$ inches.

A two-inch helium-purged, multilayer insulation (MLI) system (at 50 layers per inch) is assumed for thermal protection of the cryogenic tanks. This insulation thickness exceeds the "ground hold" thermal protection requirements for "wet-launched" $\mathrm{LH}_{2}$ tanks which need a minimum of 1.5 inches of helium-purged insulation 19. The installed density of the "2 inch MLI system" is $2.62 \mathrm{~kg} / \mathrm{m}^{2}$, and the resulting $\mathrm{LH}_{2}$ boiloff rate in LEO is $\sim 1.31 \mathrm{~kg} / \mathrm{m} 2 /$ month (based on an estimated heat flux of $\sim 0.22 \mathrm{~W} / \mathrm{m}^{2}$ at a LEO sink temperature of $\sim 240 \mathrm{~K}$ ). In lunar orbit, where the sink temperature and heat flux are estimated to be $\sim 272 \mathrm{~K}$ and $0.32 \mathrm{~W} / \mathrm{m}^{2}$, respectively, the $\mathrm{LH}_{2}$ boiloff rate increased by $\sim 46 \%$ to $1.91 \mathrm{~kg} / \mathrm{m}^{2} / \mathrm{month}$. The corresponding boiloff rates for LOX are shown in Table 2. Finally, a $0.25 \mathrm{~mm}$ thick sheet of aluminum (corresponding to $\sim 0.682 \mathrm{~kg} / \mathrm{m}^{2}$ ) is included in the total tank weight estimates to account for micrometeroid protection.

Table 1. Reference Lunar Mission Ground Rules and Assumptions

\begin{tabular}{|c|c|c|c|}
\hline \multirow{2}{*}{\multicolumn{2}{|c|}{ - Payload Outbound: }} & $\begin{array}{l}9.9 t \\
0.8 t\end{array}$ & $\begin{array}{l}\text { LTV crew module } \\
\text { Crew (4) and suits }\end{array}$ \\
\hline & & $\begin{array}{r}5.0-10.0 t \\
5.0 t \\
35.7-46.0 t\end{array}$ & $\begin{array}{l}\text { Lunar surface payload } \\
\text { LLV crew module } \\
\text { "Wet" LLV stage }\end{array}$ \\
\hline - & Payload Inbound: & $\begin{array}{l}9.9 t \\
0.8 t \\
0.5 t\end{array}$ & $\begin{array}{l}\text { LTV crew module } \\
\text { Crew (4) and suits } \\
\text { Lunar samples }\end{array}$ \\
\hline - & Parking Orbits: & $\begin{array}{l}407 \mathrm{~km} \\
300 \mathrm{~km}\end{array}$ & $\begin{array}{l}\text { Circular (Earth departure) } \\
\text { Circular (lunar arrival/departure) }\end{array}$ \\
\hline $\begin{array}{l}\dot{ } \\
\dot{ } \\
\dot{ } \\
\dot{ } \\
\dot{ }\end{array}$ & \multicolumn{3}{|c|}{$\begin{array}{l}\text { Trans-lunar injection } \Delta V \text { assumed to be } 3100 \mathrm{~m} / \mathrm{s}+\mathrm{g} \text {-losses } \\
\text { Lunar orbit capture/trans-Earth injection } \Delta V \text { 's assumed to be } 915 \mathrm{~m} / \mathrm{s} \\
\text { Earth return: Direct capsule entry } \\
\text { Earth gravity assist disposal } \Delta V \text { assumed to be } 194 \mathrm{~m} / \mathrm{s} \text { (for NTR system) } \\
\text { Mission duration: } 54 \text { days" ( } 2 \text { in LEO, } 7 \text { in transit, } 45 \text { days at Moon) } \\
\text { HLLV type/payload capability: "in-line" SDV/66 t to } 407 \mathrm{~km} \text { circular } \\
\text { LTV assembly scenario: } 2 \text { HLLV launches with EOR\&D (IMLEO < } 132 \mathrm{t} \text { ) }\end{array}$} \\
\hline & \multicolumn{3}{|c|}{$\begin{array}{l}\text { Chemical TLI and NTR "core" stages in LEO for } 30 \text { days prior to second } \\
\text { HLLV launch }\end{array}$} \\
\hline
\end{tabular}


Table 2. Lunar NTR Transportation System Assumptions

\begin{tabular}{|c|c|c|}
\hline - NTR System: & $\begin{array}{l}\text { External Shield Mass } \\
\text { Flight Reserve } \\
\text { Residuals } \\
\text { Cooldown (effective) }\end{array}$ & $\begin{array}{l}=\text { Cryogenic hydrogen and oxygen } \\
=940 \mathrm{~s}\left(@ \text { O/F MR }=0.0 / \mathrm{LH}_{2} \text { only }\right) \\
=647 \mathrm{~s}(@ \mathrm{O} / \mathrm{F} \mathrm{MR}=3.0) \\
=514 \mathrm{~s}(@ \mathrm{O} / \mathrm{F} \mathrm{MR}=7.0) \\
=2.84 \mathrm{~kg} / \mathrm{MWt} \text { of reactor power } \\
=1 \% \text { of total tank capacity } \\
=1.5 \% \text { of total tank capacity } \\
=3 \% \text { of usable } \mathrm{LH}_{2} \text { propellant }\end{array}$ \\
\hline - RCS System: & $\begin{array}{l}\text { Propellant } \\
\text { Isp } \\
\text { Tankage }\end{array}$ & $\begin{array}{l}=\mathrm{N}_{2} \mathrm{O}_{4} / \mathrm{MMH} \\
=320 \mathrm{~S} \\
=5 \% \text { of total RCS propellants }\end{array}$ \\
\hline $\begin{array}{l}\text { - Cryogenic } \\
\text { Tankage: }\end{array}$ & \multicolumn{2}{|c|}{$\begin{array}{l}\text { Material }=\text { "Weldalite" Al/Li alloy } \\
\begin{aligned} \text { Diameter } & =4.6-10.0 \mathrm{~m}\end{aligned} \\
\text { Geometry }=\text { Cylindrical tank with } \sqrt{2} / 2 \text { domes } \\
\text { Insulation }=2 \text { inches } \mathrm{MLI}+\text { micrometeoroid debris shield } \\
\begin{aligned} \text { LH } \mathrm{LOX} \text { Boiloff" } & =1.31 / 2.44 \mathrm{~kg} / \mathrm{m}^{2} / \text { month (LEO @ } 240 \mathrm{~K} \text { ) } \\
& =0.56 / 0 \% \mathrm{~kg} / \mathrm{m}^{2} / \text { month (in-space @ } \sim 172 \mathrm{~K} \text { ) } \\
& =1.92 / 3.68 \mathrm{~kg} / \mathrm{m}^{2} / \text { month }(\mathrm{LLO} @ \sim 272 \mathrm{~K})\end{aligned}\end{array}$} \\
\hline - Contingency: & $\begin{array}{l}\text { Engines \& external shields } \\
\text { All other dry masses }\end{array}$ & $\begin{array}{l}=15 \% \\
=15 \%\end{array}$ \\
\hline
\end{tabular}

\section{CHEMICAL AND NTR COMPARISONRESULTS}

The reference lunar scenario examined in this study assumes both cargo and piloted lander missions operating in an expendable mission mode. The chemical propulsion version of the piloted mission, which assumes a capsule reentry at mission end, is shown in Figure 13. Two flights of an "in-line" SDV, each with a payload delivery capability of $\sim 66 \mathrm{t}$, are used to launch the LTS elements into LEO. The first SDV flight launches the $\mathrm{LOX} / \mathrm{LH}_{2}$-fueled trans-lunar injection (TLI) stage which uses a portion of its propellant load in a suborbital burn maneuver to achieve orbit. The second SDV flight, 30 days later, launches the lunar orbit insertion/trans-Earth injection (LOI/TEI) stage with its crew module and four crew, along with the piloted LLV and its surface payload. The LTS elements are then assembled into an integrated vehicle via a rendezvous and docking manuever (see Figure 14a).

After 2 days in LEO for system check out, the TLI stage uses its 5 RL10 derivative engines (with Isp $\sim 465 \mathrm{~s}$ ) to inject the piloted LOI/TEI stage and lander elements on a translunar trajectory after which the TLI stage is jettisoned. Three RL10derivative engines are used in the LOI/TEI stage to capture into and depart from lunar orbit after completion of the 45-day landing mission. The LLV uses five throttleable RL10s and can deliver $5 t$ of surface payload on the piloted missions. On cargo missions, the $5 \mathrm{t}$ crew cab is removed and payloads on the order of $28 t$ can be delivered on " 1 way" trips to the lunar surface.

The relative size and mass of the chemical and NTR-powered piloted LTVs used for the reference lunar mission are shown in Figure 14 along with three additional NTR-powered piloted vehicle configurations operating in a LOX-augmented mode. The expendable "all $\mathrm{LH}_{2}$ " (MR = ) NTR vehicle is a "2 tank" configuration (Figure 14b) which is also launched using two "in line" SDVs. The first SDV flight delivers the "core" stage which is powered by two $15 \mathrm{klbf}$ bimodal NTRs each capable of generating $\sim 15 \mathrm{kWe}$ of electrical power using a hydrogen working fluid, closed Brayton cycle power conversion unit (CBC/PCU). The bimodal NTR design considered here was developed jointly by Aerojet20, Babcock and Wilcox and Energopool in the Commonwealth of Independent States (CIS). The CBC/PCU is enclosed within the conical extension of the stage thrust structure which also provides support for a $24 \mathrm{~m}^{2}$ heat pipe radiator required for the two engine 


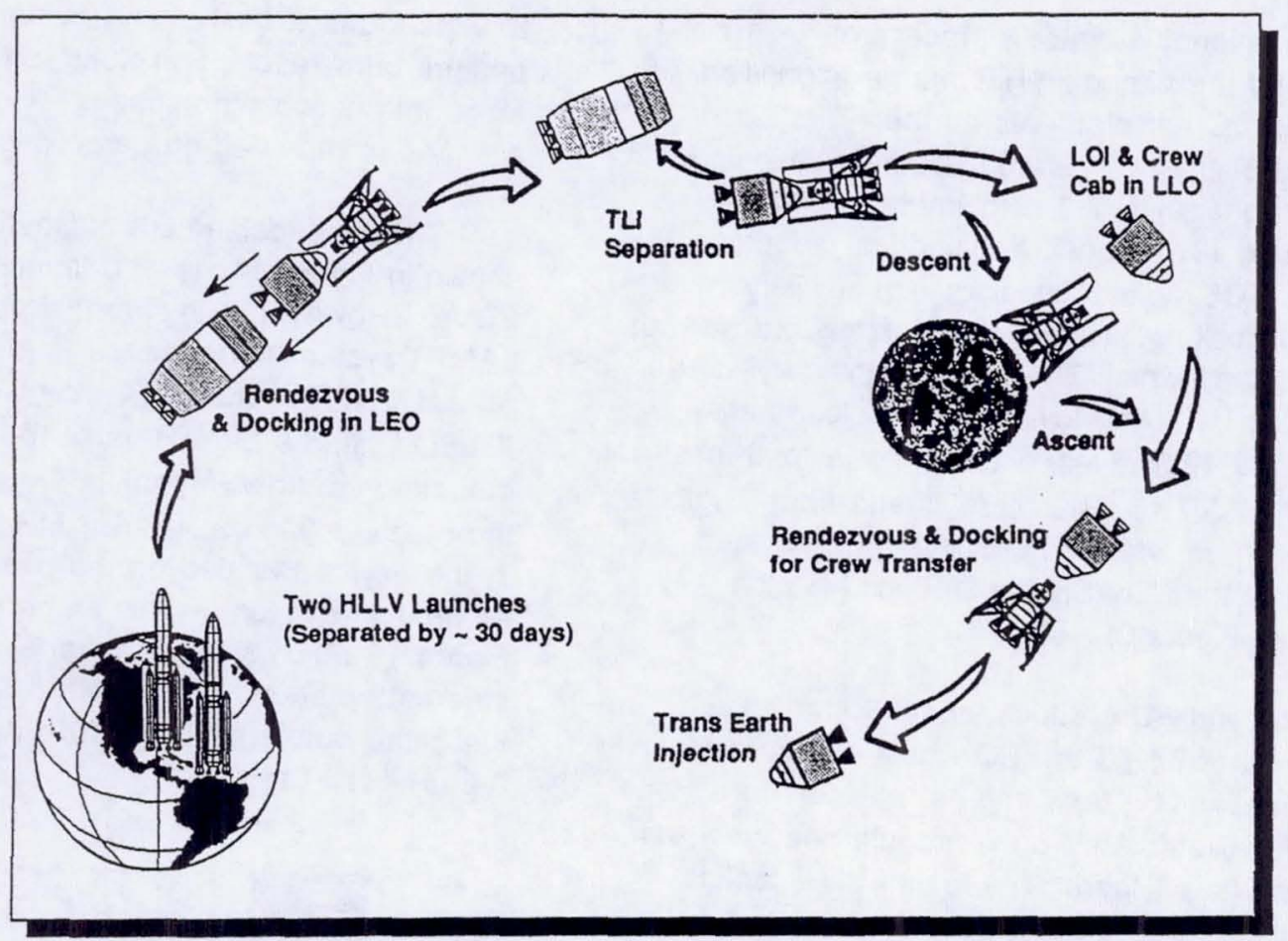

Fig. 13 Reference Piloted Lunar Mission Scenario using Two SDV Launches

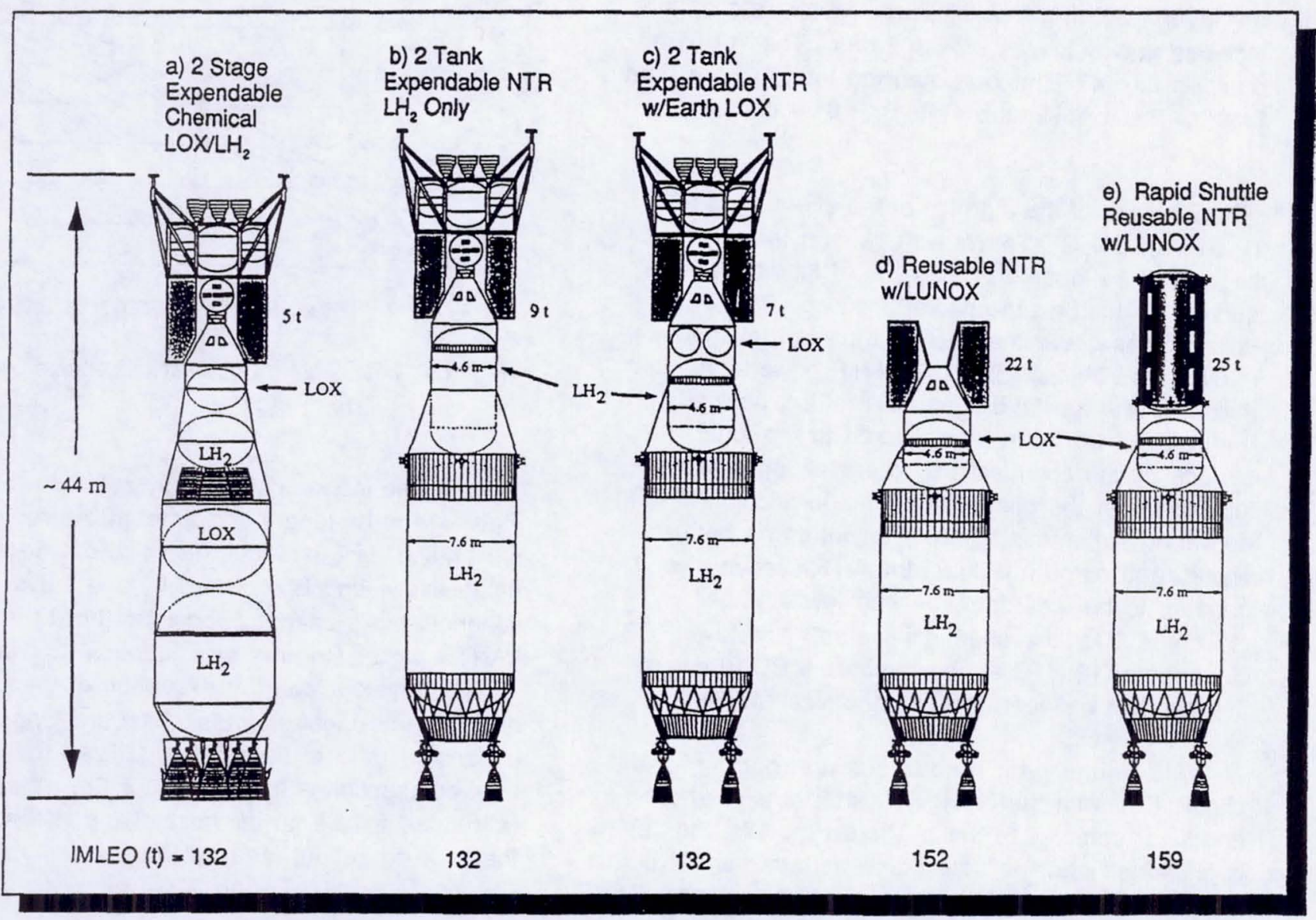

Fig. 14 Relative Size/Mass of Chemical and NTR Vehicles With and Without LOX Augmentation 
system. Additional radiator surface area $\left(\sim 13 \mathrm{~m}^{2}\right)$ is provided by the bimodal NTR's large expansion ratio nozzles. Other elements on the NTR "core" stage include: (1) two external radiation shields for crew protection; (2) a $7.6 \mathrm{~m}$ diameter by $17.5 \mathrm{~m}$ long $\mathrm{LH}_{2}$ tank; (3) a forward cylindrical adaptor housing the RCS system, avionics and auxiliary power, and docking system; and (4) forward and aft cylindrical band skirts. The mass of the "dry" core stage, and its RCS and $\mathrm{LH}_{2}$ propellant loads are $16.0,0.4$, and $49.3 \mathrm{t}$, respectively, for a total mass at liftoff of $\sim 65.7 \mathrm{t}$. The "core" stage total length is a little over $24 \mathrm{~m}$, well within the $27.4 \mathrm{~m}$ payload length limit of the SDV/Shuttle C-Block I launch vehicles (see Figure 3 ).

The second SDV launch, again 30 days later, delivers another $65.7 \mathrm{t}$ to LEO which consists of a second, smaller $\mathrm{LH}_{2}$ tank and its "conical" core stage adaptor, the piloted LTV crew module and crew, and the LLV and its payload. The "in-line" $\mathrm{LH}_{2}$ tank is $4.6 \mathrm{~m}$ in diameter and $9.0 \mathrm{~m}$ long and has a $9 \mathrm{t} \mathrm{LH}_{2}$ propellant capacity. After rendezvous and docking, the $46 \mathrm{~m}$ long NTR LTV and its payload depart for the Moon. A "single burn" Earth departure scenario includes gravity losses of $\sim 392 \mathrm{~m} / \mathrm{s}$. The TLI burn duration is $\sim 47.5$ minutes and the total mission burn time for the two $15 \mathrm{klbf}$ NTRs is $\sim 61.4$ minutes.

Because of the high Isp of the $\mathrm{LH}_{2}$-cooled NTR ( $940 \mathrm{~s}$ ), the NTR-powered LTV can transport a larger LLV to lunar orbit capable of landing $9 t$ of surface payload on the piloted mission. This is an $80 \%$ increase over the chemical system for the same number of SDV launches. For NTR-powered cargo missions with an IMLEO limit of $\sim 132 \mathrm{t}$, payloads on the order of $34 t$ can be delivered to the lunar surface by the chemical LLV representing a $378 \%$ increase over the piloted mission. In addition to delivering substantially larger payloads on both piloted and cargo missions, the NTR system also appears to be less complex with fewer stages ( 1 versus 2 for the chemical system) and fewer components ( 2 NTR engines versue $8 \mathrm{RL}-10$ derivative engines between the two chemical stages).

After lunar orbit rendezvous and docking of the piloted LLV with the NTR LTV, and transfer of crew and lunar samples to the LTV crew module, the LLV is jettisoned and the core stage performs a TEI burn to return to Earth. Following separation of the LTV crew cab for its ballistic reentry to Earth, the NTR
LTV performs a final small ( $194 \mathrm{~m} / \mathrm{s}$ ) Earth perigee burn resulting in "long-term disposal" of the stage into heliocentric space. This same disposal scenario is repeated on cargo missions also.

The expendable LOX-augmented NTR system shown in Figure $14 \mathrm{c}$ is also launched on two $66 \mathrm{t}$ SDVs. However, with "Earth-supplied" LOX only, the LANTR system performance is less than that of the "all $\mathrm{LH}_{2}{ }^{n}$ NTR system. To stay within the $132 \mathrm{t}$ IMLEO limit, the LANTR must operate with an outbound (Earth-to-Moon) MR $=0$ ("all $\mathrm{LH}_{2}$ "). As the inbound (Moon-to-Earth) MR increases from 0 to 7 , the payload landed on the piloted mission decreases from 9 to 7 tons. This same trend is depicted in Figure 15 which shows the variations in IMLEO for different outbound and inbound MR combinations for the same outbound and return payloads used on the "all $\mathrm{LH}_{2}{ }^{\text {" NTR system. }}$

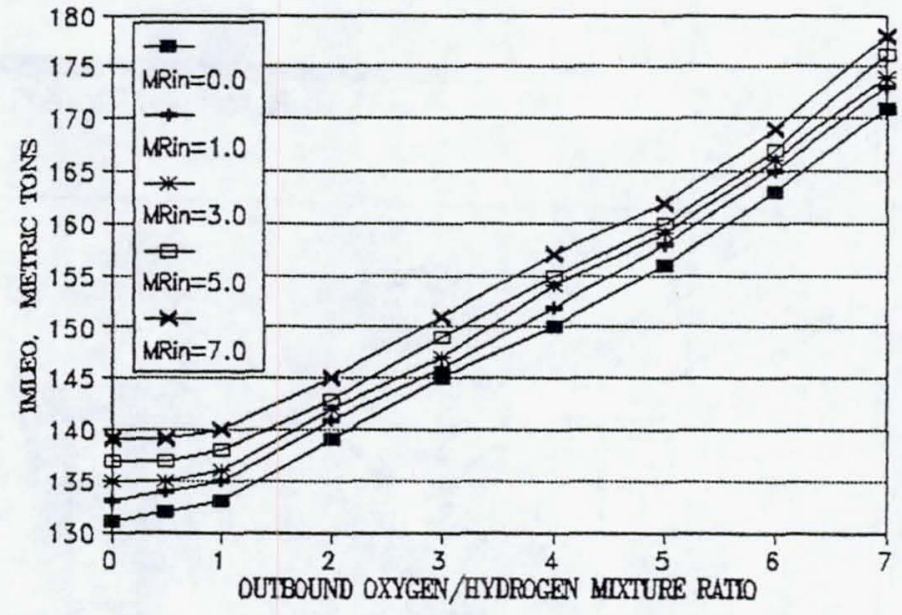

Fig. 15 IMLEO Variations with Outbound/Inbound MR (without LUNOX)

For the inbound MR = 7 system shown in Figure $14 \mathrm{c}$, the length and amount of propellant in the "in-line" $\mathrm{LH}_{2}$ tank decreases to $6.4 \mathrm{~m}$ and $\sim 6.4 \mathrm{t}$, respectively, and is replaced by two $1.8 \mathrm{~m}$ diameter spherical tanks each holding $\sim 3.4 \mathrm{t}$ of LOX. The LANTR "core" stage is also identical to that of the "all $\mathrm{LH}_{2}$ " system with the exception of the LOXaugmented $15 \mathrm{klbf}$ engines which are longer (an expansion ratio of 500-to-1 is utilized for improved LOX combustion efficiency) and $\sim 6 \%$ heavier (attributed to the larger nozzle and the addition of the LOX propellant feed system). 


\section{LANTR System Performance with LUNOX}

Once LUNOX becomes available for "reoxidizing" the LANTR LTV in LLO, the overall performance of the LTS improves dramatically. The lunar mission scenario transitions from an expendable to a "reusable" mode with the piloted LANTR system capable of delivering $\sim 27 \mathrm{t}$ of cargo and Earthsupplied $\mathrm{LH}_{2}$ into LLO. Crew and cargo are transported to the lunar surface by reusable LLVs that are now maintained and refueled at the lunar outpost.

In the reusable mode, the LLV has a reduced cargo delivery capability, however. This is due to the fact that the lander's tankage and propellant load $\left(\sim 22.3 \mathrm{t}\right.$ of $\mathrm{LOX} / \mathrm{LH}_{2}$ at MR $=6$ ) was sized to deliver $\sim 9 \mathrm{t}$ of surface payload on the initial expendable piloted missions. When the LLV (which has a "dry" mass of $11.4 \mathrm{t}$ including its $5 \mathrm{t}$ crew cab) operates from the lunar outpost, $\sim 11.5 \mathrm{t}$ of propellant is used in ascending to LLO for rendezvous with the LTV. This estimate assumes an ascent $\Delta \mathrm{V}$ of $\sim 1900 \mathrm{~m} / \mathrm{s}$ and an Isp of $\sim 465 \mathrm{~s}$ for the LLV. To land $27 \mathrm{t}$ of cargo and 4 crew on the lunar surface requires $\sim 21.7 \mathrm{t}$ of propellant assuming a descent $\Delta \mathrm{V}$ of

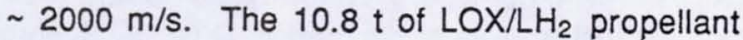
remaining in the LLV after ascent is therefore inadequate to transport this much cargo.

In the mission strategy we adopt here, the LANTR LTV is loaded with additional propellant that is transferred to the LLV after rendezvous. This "topping off" of the LLV's tanks with $10.9 \mathrm{t}$ of $\mathrm{LOX} / \mathrm{LH}_{2}$ propellant allows the crew and its entire cargo shipment to be delivered to the surface on one round trip LLV mission. Included in the $27 \mathrm{t}$ of surface cargo is $\sim 6.0 \mathrm{t}$ of $\mathrm{LH}_{2}$ propellant $(\sim 5 \mathrm{t})$ and tankage $(\sim 1 t)$ for use by the LLV on its subsequent mission.

The reusable, LOX-augmented NTR vehicle shown in Figure $14 \mathrm{~d}$ operates at a MR $=3$ (Isp $647 \mathrm{~s})$ both outbound and inbound, refuels with $\sim 21.2 \mathrm{t}$ of LUNOX for Earth return, and is a smaller overall vehicle than its expendable "all $\mathrm{LH}_{2}$ " counterpart, even with its increased performance. The oxygen tank is sized for $\sim 65 t$ of LOX of which $\sim 9.3 t$ is used for "topping off" the LLV and the remainder for the LTV's TLI and LOI manuevers. The tank diameter and overall length are both 4.6 meters. The $\mathrm{LH}_{2}$ tank shown for the reusable, piloted vehicle is $7.6 \mathrm{~m}$ in diameter and $15 \mathrm{~m}$ in length. It is only filled to $\sim 85 \%$ of its maximum capacity for this particular mission, however. Although tank size could be reduced further, the $15 \mathrm{~m}$ long tank is baselined here to provide commonality with a rapid cislunar nuclear shuttle discussed in the next section.

At $M R=3$, the thrust output from the two $15 \mathrm{klbf}$ of $\mathrm{LH}_{2}$-cooled NTRs is increased by a factor of 2.75 to $\sim 82.5 \mathrm{klbf}$. With this enhanced engine thrust-to-weight capability, the TLI burn duration and g-losses are reduced significantly to 17.2 minutes and $72 \mathrm{~m} / \mathrm{s}$, respectively, compared to 47.5 minutes and $392 \mathrm{~m} / \mathrm{s}$ for the expendable "all $\mathrm{LH}_{2}$ " NTR system. Total mission burn time is also cut in half to 28.9 minutes compared to 61.4 minutes for the expendable system. Because the LANTR engine lifetime is $\sim 4.5$ hours at hydrogen exhaust temperatures of $\sim 2900 \mathrm{~K}$, the LANTR system would be able to perform 9 round trip lunar missions in its lifetime thereby reducing LTS recurring costs.

The reusable LANTR has an IMLEO of $\sim 151.8 \mathrm{t}$ at the start of the TLI burn. This mass includes the $17.5 \mathrm{t}$ "dry" stage, a $10.7 \mathrm{t}$ piloted LTV crew module, $22.0 \mathrm{t}$ of non-propellant cargo, and RCS, $\mathrm{LH}_{2}$, and LOX propellant loads of $\sim 2.7,34.5$ and $65.0 \mathrm{t}$, respectively. In fact for initial deployment, the LANTR, with its entire RCS and $\mathrm{LH}_{2}$ propellant loads, and LTV crew module can be launched on a single SDV. The LOX tank would require on-orbit filling from an expendable propellant tanker or propellant depot. For subsequent piloted missions, the total mass to LEO needed to outfit and refuel the LTV stage is $\sim 123.2 t$ and can again be launched on two 66 t-class SDVs. Technology for autonomous rendezvous and docking and in-space propellant transfer will be required in this scenario.

Approximately $40.3 \mathrm{t}$ of LUNOX (21.2 $\mathrm{t}$ for LTV return and 19.1 for the LLV) must be produced to support this piloted mission scenario. Self-contained, modular LUNOX production units can be delivered to lunar orbit by the LANTR system and then transported to the surface using on-board chemical propulsion. Figure 16 shows an artist's sketch of a 24 metric ton per year (t/year) modular unit operating on the lunar surface. Its total mass is $\sim 17.3$ t13 which includes the mass of an $80 \mathrm{kWe}$ nuclear power system (5.2 $t$ ) for continuous lunar day/night operation, as well as, equipment for mining (3.5t), ilmenite beneficiation (3.9 t), and processing (4.8 t). 


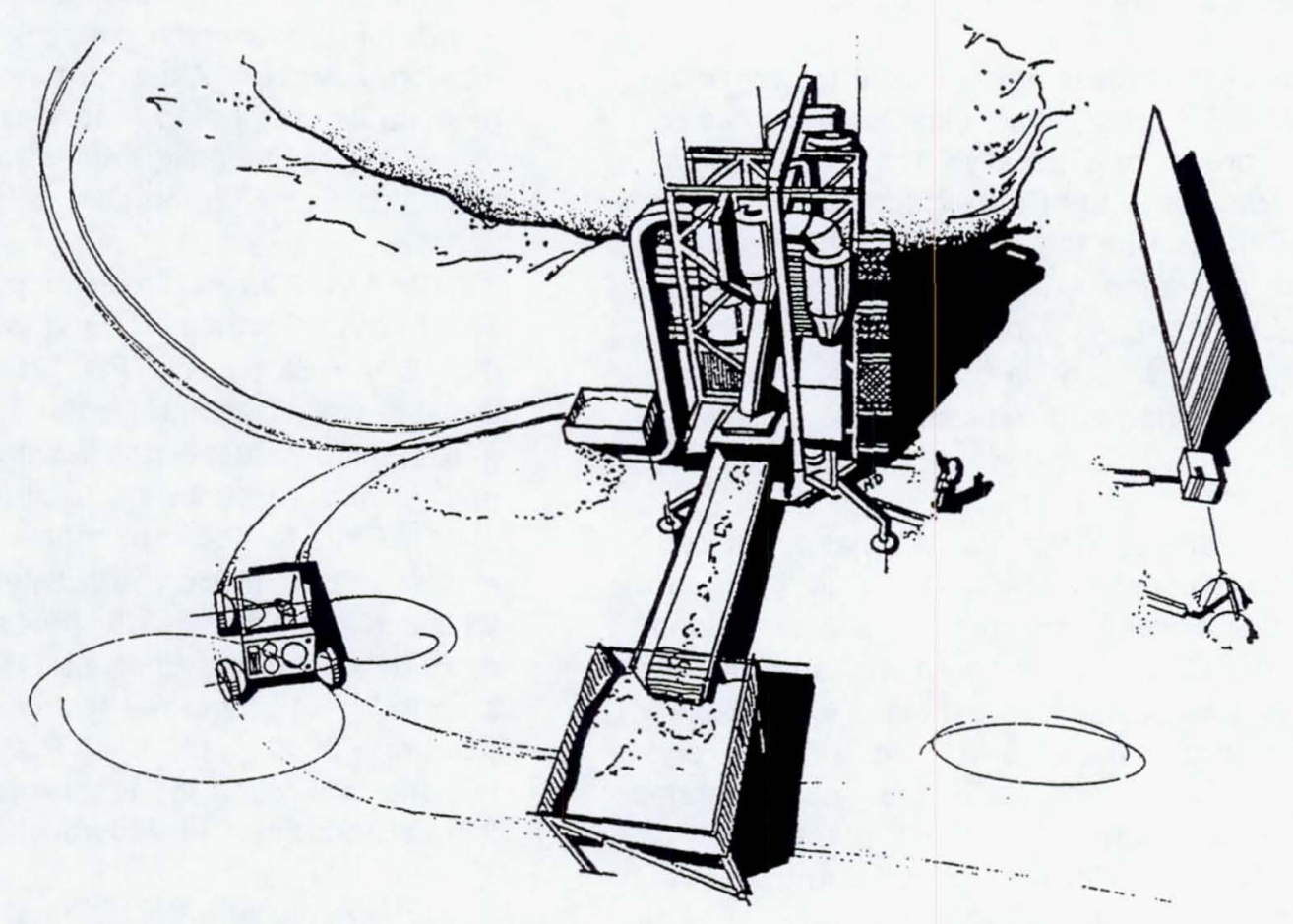

Fig. 16 Artist's Illustration of Self-Contained, Modular LUNOX Production Unit

The nuclear power system (not shown in Figure 16) would be landed separately and deployed a safe distance away from the production units. The major process equipment is approximately $4.3 \mathrm{~m}$ in diameter and $13.7 \mathrm{~m}$ long and can easily fit into the current Shuttle cargo bay. A SDV could launch the entire production unit including its power system and lunar landing stage on a single launch.

Total plant mass and power requirements will vary with the LOX production rate. In boosting capacity from 24 to 144 t/year (6 modular units), the plant mass and power levels increase from 17.3 to $63.7 \mathrm{t}$, and $\sim 81$ to $485 \mathrm{kWe}{ }^{13}$, respectively. These estimates assume the use of "soil feedstock" which has a lower ilmenite content. The landing of automated, modular LOX production units and teleoperated mining equipment is envisioned in our LANTR architecture to increase capacity gradually and provide system redundancy.

\section{Rapid Cislunar Nuclear Shuttle}

With LUNOX production underway and a reusable, LANTR LTV in service, the lunar outpost will expand to a permanent settlement staffed by visiting scientists and engineers representing both government and private commercial ventures. Convenient cislunar transportation, comparable to today's 24-hour flights from Washington, D.C., to Sydney, Australia, will make the Moon accessible to greater numbers of people and increase prospects for its commercial development. With the LANTR concept, one-way flight times to and from the Moon of 36 to 24 hours appear possible with reasonable size vehicles having attractive IMLEO values.

The $\Delta \mathrm{V}$ requirements for $\mathrm{TLI}$ and $\mathrm{LOI}$ as a function of "one-way" flight time are shown in Figure 17. For transit times less than 48 hours, the $\mathrm{TLI}$ and particularly the LOI $\Delta \mathrm{V}$ requirements increase dramatically. The "free return" to Earth option of the Apollo program is no longer available, and the outbound trajectory is that of a hyperbolic Earth departure necessitating multiple spacecraft engines for passenger safety. The "ideal" TLI and LOI total $\Delta V$ requirement, for 24 and 36 -hour transit times, are 6.9 and $5.1 \mathrm{~km} / \mathrm{s}$, respectively, compared to $\sim 4.1 \mathrm{~km} / \mathrm{s}$ for the 3.5 day reference lunar mission.

A "36-hour" LANTR shuttle capable of transporting a $25 \mathrm{t}$ passenger module to and from the Moon shown in Figure 14e. It has an IMLEO of $\sim 159 \mathrm{t}$, and is powered by two LANTR engines which produce $82.5 \mathrm{klbf}$ of thrust using an outbound and inbound $M R=3$. The shuttle's LOX tank is $4.6 \mathrm{~m}$ in diameter 


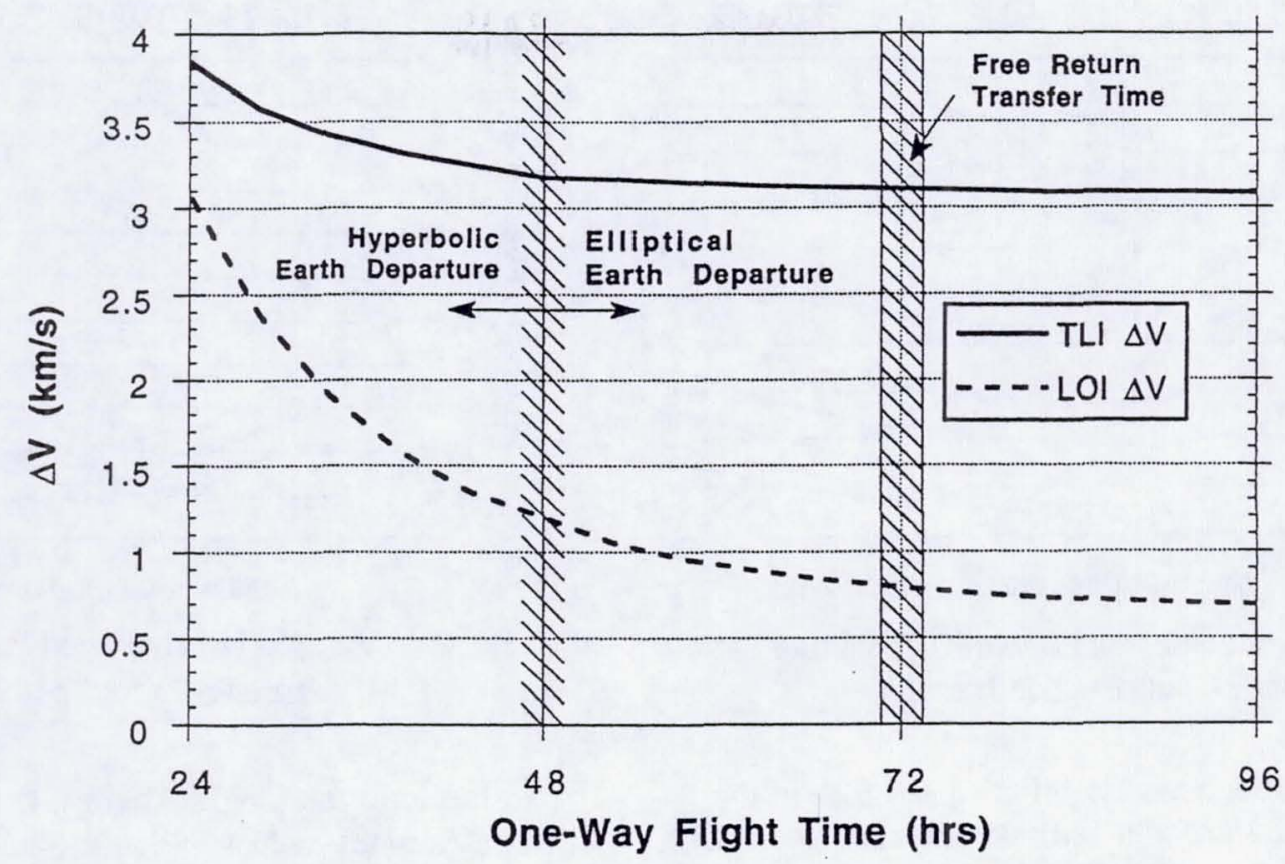

Fig. $17 \mathrm{TLI}$ and LOI $\Delta \mathrm{V}$ Variation with "1 way" Flight Time (300 km Lunar Orbit)

and $4.9 \mathrm{~m}$ long and holds $70.5 \mathrm{t}$ of Earth-supplied LOX required for the outbound trip. It is resupplied with $48.5 \mathrm{t}$ of LUNOX in LLO for the 36 -hour return trip to Earth. The spacecraft's $\mathrm{LH}_{2}$ tank is $7.6 \mathrm{~m}$ in diameter and $15 \mathrm{~m}$ long and carries the $\sim 41.5 \mathrm{t}$ of $\mathrm{LH}_{2}$ required for the round trip mission. The mass breakdown of the LANTR Shuttle includes the $20.5 \mathrm{t}$ "dry" stage, a $25 \mathrm{t}$ passenger module, and RCS, $\mathrm{LH}_{2}$ and LOX propellant loads of $1.6,41.4$, and $70.4 \mathrm{t}$,

25 TONS PAYLOAD BOTH WAYS, REUSABLE

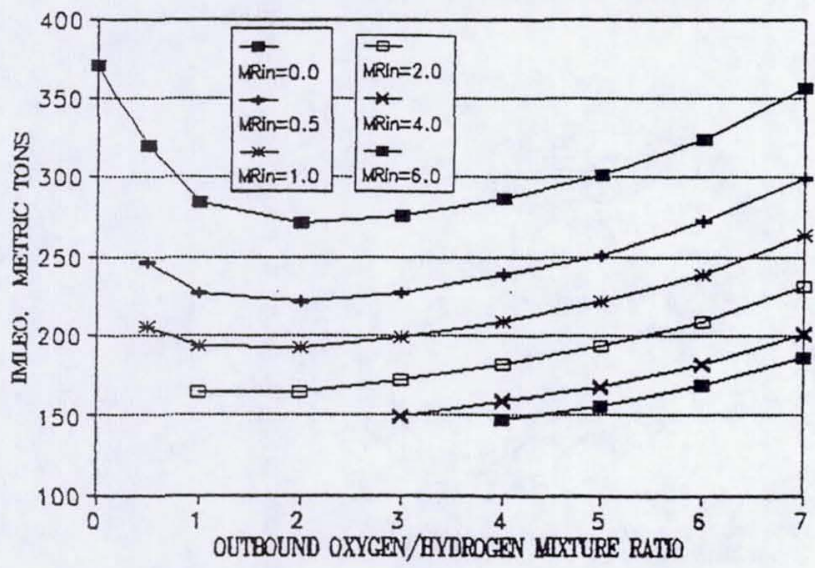

Fig. 18 Variation of IMLEO with $\mathrm{O} / \mathrm{H}$ Mixture Ratio for "36 hour" Lunar Transfer respectively. Propellant resupply from Earth for subsequent missions can again be provided by two SDV flights. The total engine burn time for this mission is also attractive being just under 45 minutes. Parametric data showing IMLEO and hydrogen tank volume variations with different outbound and inbound MR combinations is shown for 36-hour trip times in Figures 18 and 19, and for 24-hour trips in Figures 20 and 21.

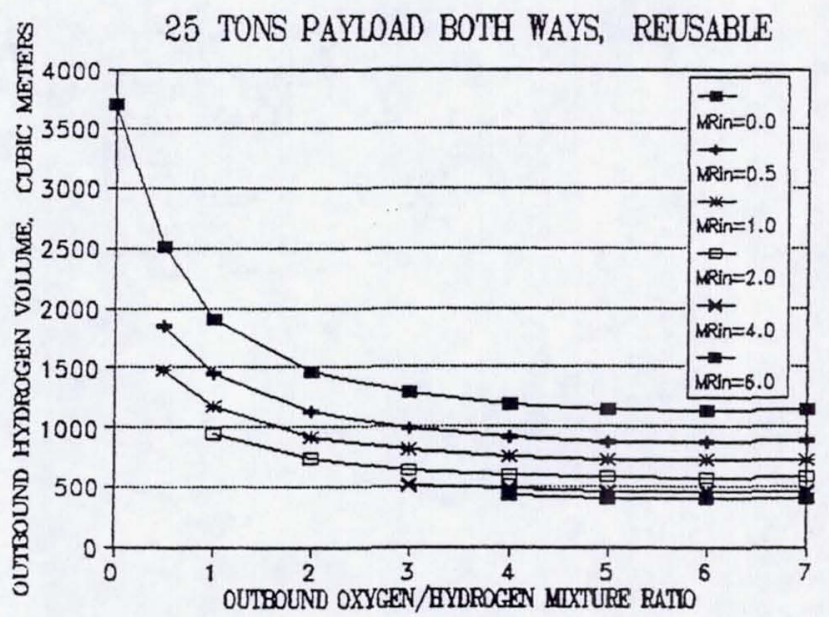

Fig. 19 Variation of Hydrogen Tank Volume with O/H Mixture Ratio for "36 hour" Lunar Transfer 
25 TONS PAYLOAD BOTH WAYS, REUSABLE

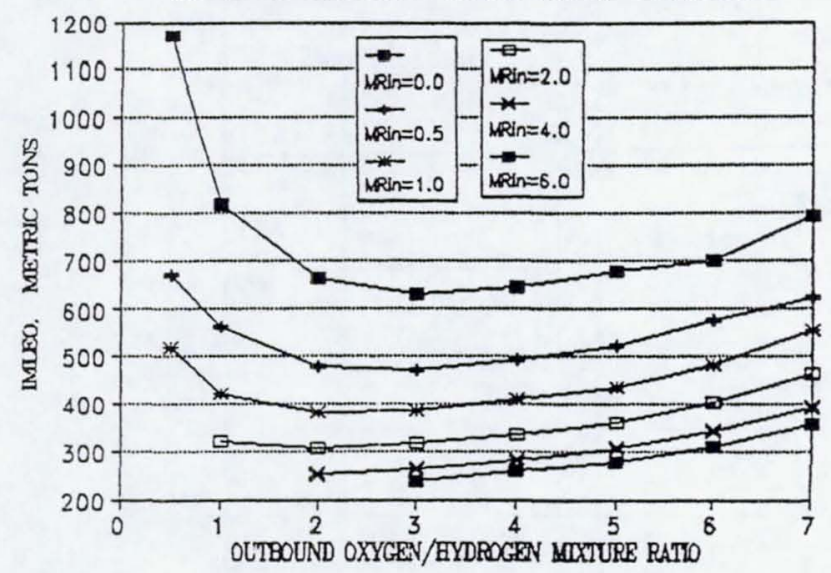

Fig. 20 Variation of IMLEO with O/H Mixture Ratio for "24 hour" Lunar Transfer

A possible scenario for a "quick trip" to the Moon would start with airbreathing/scramjet SSTO transport of passengers to an international space station (ISS). There they would enter a short duration "passenger" module containing its own life support, I\&C and auxiliary propulsion systems. The passenger module then departs the ISS and docks with a fully fueled LANTR shuttle awaiting it a safe distance away from the ISS. After a 24 to 36 -hour trip to LLO, the passenger module detaches and docks with a waiting LLV (Figure 22a) for transport

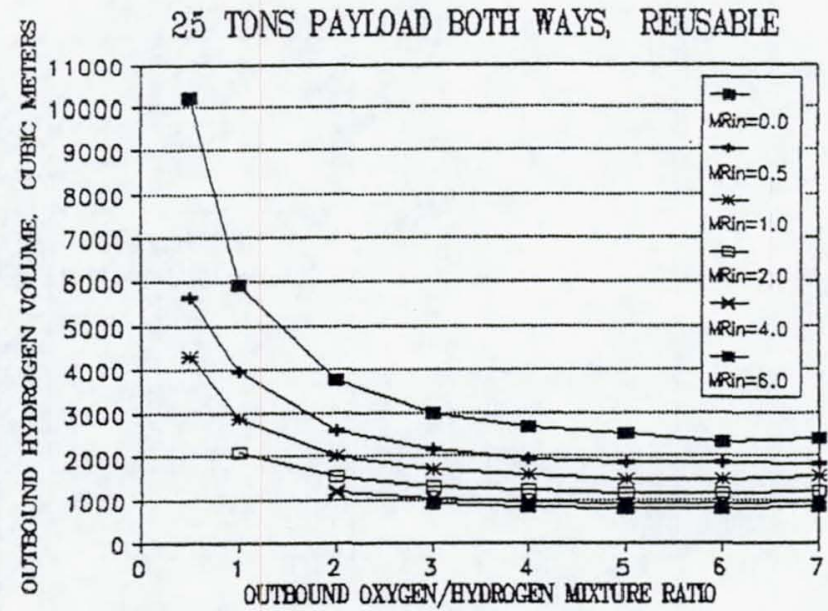

Fig. 21 Variation of Hydrogen Tank Volume with O/H Mixture Ratio for "24 hour" Lunar Transfer

to the lunar surface. There it is lowered to a "flatbed" surface vehicle (Figure 22b) for transport to the lunar base.

\section{OTHER MISSIQN APPLICATIQNS OF THE LANTR}

Besides its impressive performance for both conventional and higher energy lunar missions, the LANTR can also dramatically improve transportation system operations in the Martian system. If water is, discovered on the Martian moon, Phobos, and can be

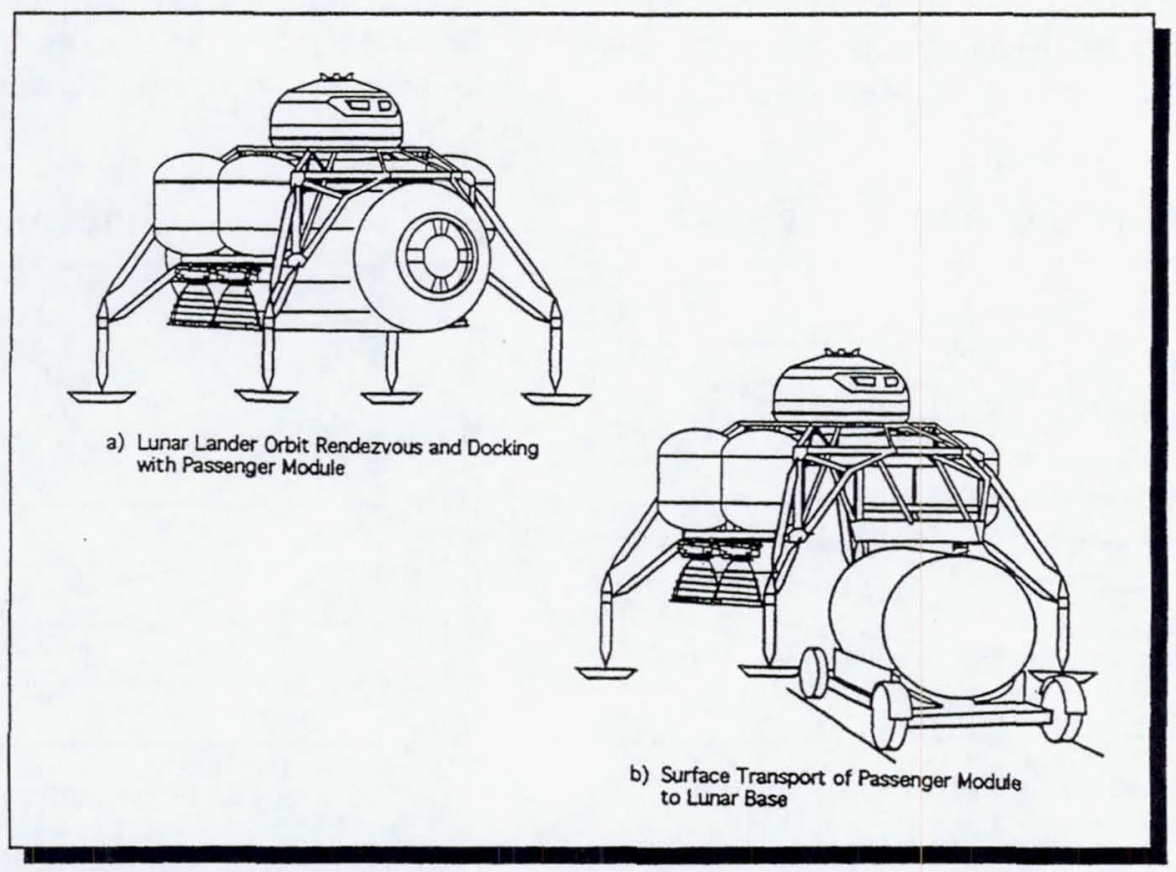

Fig. 22 Schematic of Lunar Landing Vehicle for Lunar Orbit-to-Surface Transport of "Quick Trip" Passenger Module 
recovered economically, then a Phobos propellant station could provide an important source of $\mathrm{LH}_{2}$ and LOX for "refueling and reoxidizing" LANTRpowered Mars transfer vehicles (MTVs) for their return trip to Earth.

A number of strategies for MTV use of Phobos propellant have been examined21. In terms of decreasing $\Delta V$ requirements for the MTV, options range from direct refueling of the MTV at Phobos, to MTV capture into a more energy efficient, elliptical parking orbit with its subsequent refueling by a Phobos-based tanker. With the high performance capability and operational flexibility of the LANTR concept, reduced trip times, increased payloads, and smaller MTVs are predicted for either Phobos refueling option. Spacecraft recovery in Earth orbit for subsequent reuse will also become practical with LANTR-powered systems.

A Phobos propellant station would also enable reusable Mars landing vehicles (MLVs) at reasonable size and mass thereby allowing the MTVs to transport more high value cargo to Mars in place of bulk propellant and expended lander/aerobrake hardware mass. Without a Phobos propellant source, the LANTR MTV must be refueled and/or reoxidized with propellants extracted from Mars' carbon dioxide $\left(\mathrm{CO}_{2}\right)$ atmosphere, subsurface permafrost or polar caps. A reusable, MLV using LOX-augmented NTR engines, and operating from a specially prepared landing site, could transport significant quantities of payload to or from Mars orbit. This capability is the result of the LANTR's attractive $T M$ ratio and high Isp, which at $M R=3$ is still $200 \mathrm{~s}$ higher than $\mathrm{LOX} / \mathrm{LH}_{2}$ propulsion and $275 \mathrm{~s}$ higher than LOX/methane systems.

Beyond Mars lies the asteroid belt and the Jupiter system where large quantities of water are believed to exist. Water ice has been detected on Ceres, the largest of the main-belt asteroids, and the Galilean satellites, Europa, Ganymede, and Callisto, are known to possess large amounts of water ice on their surface from the Voyager missions. With the LANTR system, extraterrestrial sources of LOX and $\mathrm{LH}_{2}$ can be accessed and utilized to facilitate human expansion into the solar system.

\section{SUMMARY AND CONCLUSIONS}

This paper introduces what we believe to be a revolutionary propulsion concept--the LOX- augmented NTR. Combining conventional $\mathrm{LH}_{2}$-cooled NTR and airbreathing/scramjet propulsion technologies, the high performance and extremely versatile LANTR provides a powerful propulsion capability to planners/designers of future human exploration missions to the Moon and beyond. Characteristics of the LANTR system include: (1) variable thrust and Isp capability; (2) "big engine" performance (i.e., augmented thrust-to-weight capability) using small, more affordable, "easier to test" NTRs; (3) reduced vehicle size brought about by the increased use of high density LOX propellant in place of low density $\mathrm{LH}_{2}$; and (4) reduced vehicle mass achieved by "reoxidizing" with LUNOX in LLO for Earth return.

An evolutionary NTR-based lunar transportation system architecture is proposed and outlined which uses only Shuttle-C or Shuttle-derived launch vehicles instead of the $150 \mathrm{t}$ HLLVs recommended in the Synthesis report. Initially, $\mathrm{LH}_{2}$-cooled NTR systems would operate in an "expendable mode" delivering $80 \%$ more payload on piloted lunar missions than their chemical propulsion counterparts. Surfacelanded payload elements are focused toward lunar resource utilization with the intent of using LUNOX for refueling the LLV and LTV elements at the earliest possible opportunity. At this point the LTS operational scenario transitions to a "reusable" mode with smaller vehicles and payload doubling benefits achieved on each piloted round-trip mission. The LANTR concept also "enables" a rapid cislunar nuclear shuttle capable of 36 to 24 hour "one-way" trip times to the Moon and back.

With its variable thrust and Isp capability and its ability to generate electrical power and utilize extraterrestrial sources of LOX and $\mathrm{LH}_{2}$, the trimodal LANTR engine can revolutionize cislunar space transportation, as well as, provide exciting prospects for the exploration of Mars and the outer solar system. On the eve of the 25th anniversary of the Apollo 11 Moon landing, it is exhilirating to contemplate the possibilities for human settlement and commercialization of the Moon which could exist before the 50th anniversary of Apollo 11 using the LOX-augmented NTR concept.

\section{ACKNOWLEDGEMENTS}

The authors wish to express thanks to the management of their respective organizations for support during the course of this study. One of the authors, Dr. Stanley K. Borowski, would also like to 
express his gratitude to the following individuals: Leon Gefert (NASA Lewis) for his analysis of the $\Delta V$ requirements for "quick trip" missions to the Moon; Ben Donahue (Boeing-Huntsville) for his analysis of advanced lunar landing vehicle design and performance; Pat Rawlings (SAIC) for artwork depicted in Figure 4; and Stephanie Black for her invaluable assistance in preparing this paper.

\section{REEERENCES}

1. C. Covault, "Manned Lunar Base, Mars Initiative Raised in Secret White House Review," Aviation Week and Space Technology, Vol. 131, No. 3, (July 17, 1989), pp.24-26.

2. A. Cohen, et al., Report of the 90-Day Study on Human Exploration of the Moon and Mars, National Aeronautics and Space Administration (November 1989).

3. C. C. Priest and G. R. Woodcock, "Space Transportation Systems Supporting a Lunar Base," AlAA-90-0422, American Institute of Aeronautics and Astronautics (1990).

4. B. Roberts and L. Pieniazek, "Surface Systems Supporting a Lunar Base," AlAA-90-0423, American Institute of Aeronautics and Astronautics (1990).

5. America at the Threshold--America's Space Exploration Initiative, Report of the Synthesis Group, Available from the Superintendent of Documents, U.S. Government Printing Office, Washington, DC 20402 (June 1991).

6. S. K. Borowski, "The Rationale/Benefits of Nuclear Thermal Rocket Propulsion for NASA's Lunar Space Transportation System," AIAA-91-2052, American Institute of Aeronautics and Astronautics (1991).

7. T. S. Sullivan and D. S. McKay, Using Space Resources, NASA Johnson Space Center (1991).

8. B. Sherwood and G. R. Woodcock, "Cost and Benefits of Lunar Oxygen: Economics, Engineering and Operations," Besources of Near Earth Space, J. Lewis et al., eds., The University of Arizona Press (1993).

9. "Analysis of the Synthesis Group's Space Resource Utilization Architecture," ExPO Document XE-92-004 (February 1992).
10. H. H. Koelle, "The Influence of Lunar Propellant Production on the Cost-Effectiveness of Cis-Lunar Transportation Systems," The Second Conference on Lunar Bases and Space Activities of the 21st Century, Houston, Texas, April 5-7, 1988, pp. $447-$ 452.

11. H. P. Davis and W. R. Stump, "Lunar Oxygen Impact Upon STS Effectiveness," Eagle Engineering Repert No. 83-63, Eagle Engineering, Inc., Houston, Texas, (May 1983).

12. W. R. Stump, E. L. Christiansen, G. Babb, and D. Sullivan, "Analysis of Lunar Propellant Production," Eagle Engineering Repert No. 85-103B, Eagle Engineering, Inc., Houston, Texas (Dec. 9, 1985).

13. E. L. Christiansen, et al., "Conceptual Design of a Lunar Oxygen Pilot Plant," Eagle Engineering Report No. 88-182, Eagle Engineering, Inc., Houston, Texas (July 1, 1988).

14. W. S. Rutledge, "Launch Vehicle Cost Trends," Aerospace America, Vol. 32, (June 1994).

15. B. K. Joosten and L. A. Guerra, "Early Lunar Resource Utilization: A Key to Human Exploration," AlAA-93-4784, American Institute of Aeronautics and Astronautics (Sept. 1993).

16. D. Kingsbury, "A Hybrid Chemical-Nuclear Space Freighter Concept," The Industrialization of Space, R. A. Van Patten et al., eds., American Astronautical Society Publication, October 18-20, 1977, Vol. 36, pp. 139-156.

17. F. S. Billig, R. C. Orth, and M. Lasky, "A Unified Analysis of Gaseous Jet Penetration," AlAA Journal, Vol. 9, (June 1971), pp. 1048-1058.

18. "Space Transfer Vehicle Concepts and Requirements Study," Martin Marietta, Denver, Colorado, Marshall Space Flight Center Space Transportation Week \#5 Report, December 4, 1991.

19. R. H. Knoll, R. J. Stochl, and R. Sanabria, "A Review of Candidate Multilayer Insulation Systems for Potential Use on Wet-Launched $\mathrm{LH}_{2}$ Tankage for the Space Exploration Initiative Lunar Mission," AlAA-91-2176, American Institute of Aeronautics and Astronautics (June 1991). 
20. D. W. Culver, V. Kolganov, and R. Rochow, "Low

Thrust, Deep Throttling, US/CIS Integrated NTRE,"

11 th Symposium on Space Nuclear Power Systems,

Albuquerque, New Mexico, (January 9-13, 1994).

21. B. C. Clark, "Mission and Transportation Applications of In-Situ Propellant Production in the Mars System," Resources of Near Earth Space, J. Lewis et al., eds., The University of Arizona Press (1993). 
Public reporting burden for this collection of information is estimated to average 1 hour per response, including the time for reviewing instructions, searching existing data sources, gathering and maintaining the data needed, and completing and reviewing the collection of information. Send comments regarding this burden estimate or any other aspect of this
collection of information, including suggestions for reducing this burden, to Washington Headquarters Services, Directorate for Information Operations and Reports, 1215 Jefferson Davis Highway, Suite 1204, Arlington, VA 22202-4302, and to the Office of Management and Budget, Paperwork Reduction Project (0704-0188), Washington, DC 20503.

\begin{tabular}{|l|l|r|}
\hline 1. AGENCY USE ONLY (Leave blank) & $\begin{array}{c}\text { 2. REPORT DATE } \\
\text { August } 1994\end{array}$ & $\begin{array}{r}\text { 3. REPORT TYPE AND DATES COVERED } \\
\text { Technical Memorandum }\end{array}$
\end{tabular}

4. TITLE AND SUBTTILE

5. FUNDING NUMBERS

A Revolutionary Lunar Space Transportation System Architecture Using Extraterrestrial LOX-Augmented NTR Propulsion

6. AUTHOR(S)

Stanley K. Borowski, Robert R. Corban, Donald W. Culver, Melvin J. Bulman, and Mel C. McIlwain

7. PERFORMING ORGANIZATION NAME(S) AND ADDRESS(ES)

National Aeronautics and Space Administration

Lewis Research Center

Cleveland, Ohio 44135-3191

WU-None

9. SPONSORING/MONITORING AGENCY NAME(S) AND ADDRESS(ES)

National Aeronautics and Space Administration

Washington, D.C. 20546-0001
8. PERFORMING ORGANIZATION REPORT NUMBER

E-9096

10. SPONSORING/MONITORING AGENCY REPORT NUMBER

NASA TM-106726

AIAA-94-3343

\section{SUPPLEMENTARY NOTES}

Prepared for the 30th Joint Propulsion Conference cosponsored by AIAA, ASME, SAE, and ASEE, Indianapolis, Indiana, June 27-29, 1994. Stanley K. Borowski and Robert R. Corban, NASA Lewis Research Center, Donald W. Culver, Melvin J. Bulman, and Mel C. McIlwain, Aerojet Propulsion Division, Sacramento, Califomia 95813. Responsible person, Stanley K. Borowski, organization code 6850, (216) 433-7091.

12a. DISTRIBUTION/AVAILABILTTY STATEMENT

12b. DISTRIBUTION CODE

Unclassified -Unlimited

Subject Categories 16 and 20

\section{ABSTRACT (Maximum 200 words)}

The concept of a liquid oxygen (LOX)-augmented nuclear thermal rocket (NTR) engine is introduced, and its potential for revolutionizing lunar space transportation system (LTS) performance using extraterrestrial "lunar-derived" liquid oxygen (LUNOX) is outlined. The LOX-augmented NTR (LANTR) represents the marriage of conventional liquid hydrogen $\left(\mathrm{LH}_{2}\right)$-cooled NTR and airbreathing engine technologies. The large divergent section of the NTR nozzle functions as an "afterburner" into which oxygen is injected and supersonically combusted with nuclear preheated hydrogen emerging from the NTR's choked sonic throat--"scramjet propulsion in reverse." By varying the oxygen-to-fuel mixture ratio (MR), the LANTR concept can provide variable thrust and specific impulse (lsp) capability with a $\mathrm{LH}_{2}$-cooled NTR operating at relatively constant power output. For example, at a $M R=3$, the thrust per engine can be increased by a factor of 2.75 while the lsp decreases by only $30 \%$. With this thrust augmentation option, smaller "easier to develop" NTRs become more acceptable from a mission performance standpoint (e.g., Earth escape gravity losses are reduced and perigee propulsion requirements are eliminated). Hydrogen mass and volume is also reduced resulting in smaller space vehicles. An evolutionary NTR-based lunar architecture, requiring only Shuttle C and/or "in-line" Shuttle-derived launch vehicles (SDVs), would operate initially in an "expendable mode" with $\mathrm{LH}_{2}$-cooled NTR lunar transfer vehicles (LTVs) delivering $80 \%$ more payload on piloted missions than their $\mathrm{LOX}_{\mathrm{LH}}$ chemical propulsion counterparts. With the establishment of LUNOX production facilities on the lunar surface and a "fuel/oxidizer" depot in low lunar orbit (LLO), monopropellant NTRs would be outfitted with an oxygen propellant module, feed system and afterburner nozzle for "bipropellant" operation. The LANTR cislunar LTV now transitions to a reusable mode with smaller vehicle and payload doubling benefits on each piloted round trip mission. As the initial lunar outposts grow to centralized bases and settlements with a substantial permanent human presence, a LANTR-powered shuttle capable of 36 to 24 hour "one-way" trip times to the Moon and back becomes possible with initial mass in low Earth orbit (IMLEO) requirements of $\sim 160$ to 240 metric tons, respectively.

\section{SUBJECT TERMS}

Nuclear thermal rocket; NTR; LUNOX; Lunar-oxygen; Scramjet cascade injector 15. NUMBER OF PAGES 23

\begin{tabular}{|c|c|}
\hline $\begin{array}{c}\text { 17. SECURTY CLASSIFICATION } \\
\text { OF REPORT } \\
\text { Unclassified }\end{array}$ & $\begin{array}{c}\text { 18. SECURITY CLASSIFICATION } \\
\text { OF THIS PAGE } \\
\text { Unclassified }\end{array}$ \\
\hline
\end{tabular}

19. SECURITY CLASSIFICATION OF ABSTRACT Unclassified 